\title{
Sequence variant analysis of RNA sequences in severe equine asthma
}

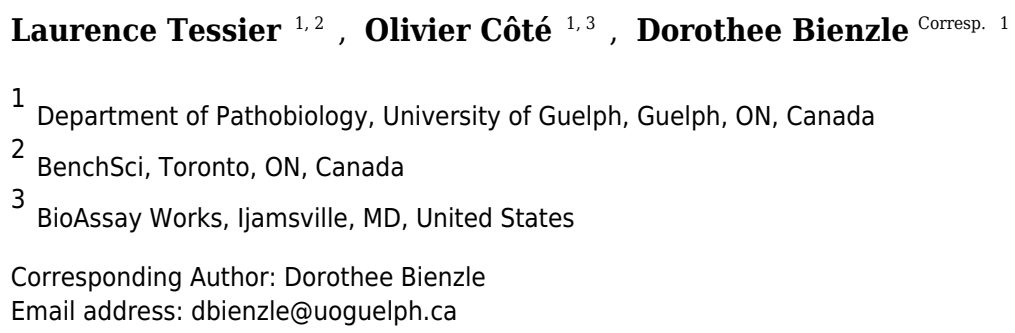

Background. Severe equine asthma is a chronic inflammatory disease of the lung in horses similar to low-Th2 late-onset asthma in humans. This study aimed to determine the utility of RNA-Seq to call gene sequence variants, and to identify sequence variants or potential relevance to the pathogenesis of asthma. Methods. RNA-Seq data were generated from endobronchial biopsies collected from 6 asthmatic and 7 non-asthmatic horses before and after challenge (26 samples total). Sequences were aligned to the equine genome with Spliced Transcripts Alignment to Reference software. Read preparation for sequence variant calling was performed with Picard tools and Genome Analysis Toolkit (GATK). Sequence variants were called and filtered using GATK and Ensembl Variant Effect Predictor (VEP) tools, and two RNA-Seq predicted sequence variants were investigated with both PCR and Sanger sequencing. Supplementary analysis of novel sequence variant selection with VEP was based on a score of $<0.01$ predicted with Sorting Intolerant From Tolerant (SIFT) software, missense nature, location within the protein coding sequence and presence in all asthmatic individuals. For select variants, effect on protein function was assessed with Polymorphism Phenotyping (PolyPhen) 2 and Screening for Non-Acceptable Polymorphism (SNAP) 2 software. Sequences were aligned and 3D protein structures predicted with Geneious software. Difference in allele frequency between the groups was assessed using a Pearson's Chi-squared test with Yates' continuity correction, and difference in genotype frequency was calculated using the Fisher's exact test for count data. Results. RNA-Seq variant calling and filtering correctly identified substitution variants in PACRG and $R T T N$. Sanger sequencing confirmed that the $P A C R G$ substitution was appropriately identified in all 26 samples while the $R T T N$ substitution was identified correctly in 24 of 26 samples. These variants of uncertain significance had substitutions that were predicted to result in loss of function and to be non-neutral. Amino acid substitutions projected no change of hydrophobicity and 
isoelectric point in PACRG, and a change in both for RTTN. For PACRG, no difference in allele frequency between the two groups was detected but a higher proportion of asthmatic horses had the altered RTTN allele compared to non-asthmatic animals.

Discussion. RNA-Seq was sensitive and specific for calling gene sequence variants in this disease model. Even moderate coverage $(<10-20 \mathrm{cpm})$ yielded correct identification in $92 \%$ of samples, suggesting RNA-Seq may be suitable to detect sequence variants in low coverage samples. The impact of amino acid alterations in PACRG and RTTN proteins, and possible association of the sequence variants with asthma, is of uncertain significance, but their role in ciliary function may be of future interest. 
1 Sequence variant analysis of RNA sequences in severe equine asthma

2

3 Laurence Tessier ${ }^{1, \#}$, Olivier Côté ${ }^{1, *}$, Dorothee Bienzle ${ }^{1, * *}$

4

$5{ }^{1}$ Department of Pathobiology, University of Guelph, 50 Stone Road East, Guelph, Ontario N1G

$62 \mathrm{~W} 1$, Canada

7

8 \#Current address: BenchSci, 559 College St., Suite 201, Toronto, ON M6G 1A9

$9{ }^{*}$ Current address: BioAssay Works, 10075 Tyler Place, Suite 18, Ijamsville, MD 21754, USA

10

$11{ }^{* *}$ Corresponding author: dbienzle@uoguelph.ca

12

13

14

15

16

17

18

19

20

21

22

23

24

25

26

27

28

29

30

31 
32 ABSTRACT

33 Background. Severe equine asthma is a chronic inflammatory disease of the lung in horses 34 similar to low-Th2 late-onset asthma in humans. This study aimed to determine the utility of 35 RNA-Seq to call gene sequence variants, and to identify sequence variants or potential relevance 36 to the pathogenesis of asthma.

37 Methods. RNA-Seq data were generated from endobronchial biopsies collected from 6 asthmatic 38 and 7 non-asthmatic horses before and after challenge (26 samples total). Sequences were 39 aligned to the equine genome with Spliced Transcripts Alignment to Reference software. Read 40 preparation for sequence variant calling was performed with Picard tools and Genome Analysis Toolkit (GATK). Sequence variants were called and filtered using GATK and Ensembl Variant

Effect Predictor (VEP) tools, and two RNA-Seq predicted sequence variants were investigated with both PCR and Sanger sequencing. Supplementary analysis of novel sequence variant selection with VEP was based on a score of $<0.01$ predicted with Sorting Intolerant From 5 Tolerant (SIFT) software, missense nature, location within the protein coding sequence and presence in all asthmatic individuals. For select variants, effect on protein function was assessed 48 49 with Polymorphism Phenotyping (PolyPhen) 2 and Screening for Non-Acceptable Polymorphism (SNAP) 2 software. Sequences were aligned and 3D protein structures predicted with Geneious software. Difference in allele frequency between the groups was assessed using a Pearson's Chi-squared test with Yates' continuity correction, and difference in genotype frequency was calculated using the Fisher's exact test for count data. Results. RNA-Seq variant calling and filtering correctly identified substitution variants in $P A C R G$ and $R T T N$. Sanger sequencing confirmed that the $P A C R G$ substitution was appropriately identified in all 26 samples while the RTTN substitution was identified correctly in 24 of 26 samples. These variants of uncertain significance had substitutions that were predicted to result in loss of function and to be non-neutral. Amino acid substitutions projected no change of hydrophobicity and isoelectric point in PACRG, and a change in both for RTTN. For PACRG, no difference in allele frequency between the two groups was detected but a higher proportion of asthmatic horses had the altered RTTN allele compared to non-asthmatic animals.

60 Discussion. RNA-Seq was sensitive and specific for calling gene sequence variants in this 61 disease model. Even moderate coverage $(<10-20 \mathrm{cpm})$ yielded correct identification in $92 \%$ of samples, suggesting RNA-Seq may be suitable to detect sequence variants in low coverage 
63 samples. The impact of amino acid alterations in PACRG and RTTN proteins, and possible

64 association of the sequence variants with asthma, is of uncertain significance, but their role in 65 ciliary function may be of future interest.

66

67

68 


\section{INTRODUCTION}

70 Severe equine asthma (recurrent airway obstruction, heaves) is a chronic inflammatory lung

71 disease caused by inhalation of environmental dust and microbial components [1]. Exacerbation

72 of the disease triggers excessive mucus production, cough, neutrophilic airway inflammation,

73 bronchial hyperreactivity, and bronchospasm. Recurrent exacerbations induce smooth muscle

74 hyperplasia and hypertrophy, fibrosis and eventual irreversible airway remodeling [2-5].

Asthma in humans is recognized to be a heterogeneous disease that is classified considering genetic, molecular and clinical features [6,7]. Severe equine asthma is most similar to human severe, late-onset asthma characterized by absence of Th2 cytokines, and presence of neutrophilic inflammation and bronchial neutrophil chemokines [6,8]. Severely asthmatic horses do not have a hypersensitivity response [2] and efforts to associate equine asthma with a Th2 cytokine profile have yielded inconsistent or inconclusive results [9-17]. Mechanisms leading to the development of both severe equine asthma and late-onset low-Th2 severe asthma in humans remain largely undefined.

Interactions between genes and environmental factors have been recognized to contribute to development of equine asthma for many years [18]. Genetic factors likely reside in multiple gene sequence variants, and may be influenced by age and sex [18-20]. Several susceptibility sequence variants, haplotypes and regions have been associated with human asthma [21-34] but no specific markers have been identified in the late-onset low-Th2 sub-phenotype [6,8]. Similarly, genetic markers of equine severe asthma were identified in certain families, but were not significantly associated across different families and genetic backgrounds [20,35-38].

RNA-Seq is a promising approach for calling sequence variants concurrent with analysis of gene and allele-specific expression, alternative splicing, and pathways. In this study we investigated whether SNV detected by RNA-Seq were also present in Sanger-sequenced amplicons. We hypothesized that RNA-Seq would identify gene sequence variants with high accuracy.

\section{METHODS}

\section{Animals and procedures}

Animal and sample procedures were previously described [39]. Briefly, six asthmatic and seven non-asthmatic horses without signs of asthma exacerbation belonging to the institutional research 
100 herd (mean ages of 15 and 12 years, respectively, $p=0.352$, unpaired t test) were placed indoor

101 in a dust-free environment. After 24 hours, asthmatic horses were exposed to dusty hay until

102 exacerbation (range 1 to 3 days, average 2.2 days), while non-asthmatic horses were exposed for

1033 days. Before and after the dusty hay asthmatic challenge, physical examination, pulmonary

104 function test, and bronchoalveolar lavage were performed, and endoscopic bronchial biopsies

105 were collected from lung lobes contralateral between first and second samples. Samples from an

106 additional four asthmatic and seven non-asthmatic horses were used for PCR-amplification of

107 specific sequence variant regions and Sanger sequencing. All procedures were approved by the

108 Institutional Animal Care Committee of the University of Guelph (protocol R10-031) and

109 conducted in compliance with Canadian Council on Animal Care guidelines.

110

\section{RNA-Seq sample preparation and sequence alignment}

112 RNA extraction, preparation and sequencing procedures were as described previously [39]. In

113 brief, total RNA was extracted from endobronchial biopsies (Qiagen, Toronto, ON) and tested

114 for quality and concentration with the Bioanalyzer RNA Nanochip (Agilent, Mississauga, ON)

115 and capillary electrophoresis. RNA-Seq library preparation (unstranded) and sequencing were

116 performed using the Illumina TruSeq RNA sample preparation and appropriate sequencing

117 protocols (Illumina, San Diego, CA) at The Centre for Applied Genomics (TCAG; Toronto,

$118 \mathrm{ON})$. Sequencing of 100-base paired-end reads was performed following the manufacturer's

119 instructions on an Illumina HiSeq 2500 instrument.

120 FastQC software version 0.10 .1 (bioinformatics.babraham.ac.uk/projects/fastqc/) was

121 used to assess quality of raw reads, and alignment to the horse reference genome [40] (Ensembl

122 v70) was performed with STAR version 2.4 [41]. Specifically, the STAR_pass2 alignment

123 protocol was followed using the horse Ensembl version 70 GTF annotation file for first- and

124 second-pass, and the junction SJ.tab file generated by STAR for the second-pass after non-

125 canonical junctions were removed. Default settings were used except for: --runThreadN 8 --

126 outFilterScoreMinOverLread 0.5 --outFilterMatchNminOverLread 0.5. Details and results for

127 read alignment were previously described [39].

128

129 Sequence variant calling and filtering 
130 Read processing, sequence variant calling and initial filtering were performed following the

131 Genome Analysis ToolKit (GATK) best practice guide for variant calling on RNA-Seq, except

132 for the Indel realignment step considering the pass-2 STAR alignment initially performed. Initial

133 read processing was first performed with Picard tools version 1.114

134 (broadinstitute.github.io/picard/) to add read groups and mark duplicates. Split n' Trim as well as

135 base recalibration were performed using the GATK software version 3.2.2 [42] and the $-T$

136 SplitNCigarReads, -rf ReassignOneMappingQuality, -RMQF 255, -RMQT 60 and -U

137 ALLOW_N_CIGAR_READS options.

138 The GATK variant calling and filtering workflow yielded 2,823 and 1,788 sequence

139 variants present in all horses of the asthmatic group pre- and post-challenge, respectively (Suppl.

140 Figure 1). Sequence variants were subsequently called using the Haplotype Caller function in

141 GATK with the same genome annotation file used in the read alignment phase and the following

142 options: -recoverDanglingHeads, -dontUseSoftClippedBases, -stand_call_conf 20.0 and -

143 stand_emit_conf 20.0 options. Resultant sequence variants were processed with the variant

144 filtration function of GATK software and the following options to establish a confidence

145 threshold of reported variants: -window 35, -cluster 3, -filterName FS, -filter "FS > 30.0", -

146 filterName $Q D$ and -filter " $Q D<2.0$ ". Sequence variants were analyzed individually in each of

14726 samples (6 asthmatics and 7 non-asthmatics, before and after asthmatic challenge).

148

149 PCR

150 Primers for amplification of sequence variant regions from bronchial DNA were parkin co151 regulated $(P A C R G)$ forward (5'-CTC TGA ACC TCC GAA ACC GAC-3') and reverse (5'-CTC 152 CTG GGA TAA CTC ACC ATT C-3'), and rotatin (RTTN) forward (5'-TCC TGA GTT GTA 153 TCA AGA AGT G-3') and reverse (5'-CCA GCC TGC AAT TCC TTT CT-3'). A Taq 154 polymerase PCR kit (Invitrogen, Mississauga, ON) was used for PCR amplifications. Each 155 reaction was performed in a $25 \mu \mathrm{L}$ final volume, including $5 \mu \mathrm{L}$ of 10X PCR buffer, $0.2 \mathrm{mM}$ $156 \mathrm{dNTPs}, 2 \mathrm{mM} \mathrm{MgSO}_{4}, 0.3 \mu \mathrm{M}$ of each primer, $2 \mathrm{U}$ of Platinum Taq, and $5 \mu \mathrm{L}$ (100 ng) of 157 template DNA. PCR conditions for amplification were $3 \mathrm{~min}$ at $94{ }^{\circ} \mathrm{C}$ followed by 35 cycles of $15894{ }^{\circ} \mathrm{C}$ for $45 \mathrm{~s}, 60{ }^{\circ} \mathrm{C}$ or $58^{\circ} \mathrm{C}$ for $30 \mathrm{~s}$ for $P A C R G$ and $R T T N$, respectively, and $72{ }^{\circ} \mathrm{C}$ for $90 \mathrm{sec}$, 159 followed by final elongation for $10 \mathrm{~min}$ at $72{ }^{\circ} \mathrm{C}$. Twenty $\mu \mathrm{L}$ of each PCR product was separated 160 by electrophoresis in a 1\% agarose gel stained with SYBR Safe (Invitrogen). Amplicons of 
161 appropriate size were cut out and DNA extracted and purified (QIAquick, Qiagen). Extracted 162 and purified PCR products were Sanger sequenced (Laboratory Services Division, Guelph, ON).

163

\section{RESULTS}

\section{Sequence variant calling and filtering}

166 The mean of the total number of RNA-Seq reads for all samples was 36,252,701.08, and the

167 mean of uniquely mapped number of reads was 33,127,466.35. The number of individual total

168 reads, total mapped reads, uniquely mapped reads and multiple mapped reads is detailed

169 elsewhere (39). The GATK workflow resulted in 2,823 and 1,788 sequence variants present

170 specifically in the asthmatic group pre- and post-challenge, respectively (Suppl. Figure 1). Of

171 these, 10 were missense substitution variants, coded for proteins and had SIFT scores $<0.01$.

172 Substitution variants in PACRG (Fig. 1A) and RTTN (Fig. 1B) were detected at higher proportion

173 in asthmatic compared to non-asthmatic horses. A missense G/A substitution was detected in the

174 coding sequence of $P A C R G$ at position 265,643 (Ensembl sequence ENSECAG00000014308)

175 /264,806 (NCBI accession number 100050378) (Fig. 1A). A missense T/A substitution was

176 detected in the coding sequence of RTTN at position 27,190 (Ensembl sequence

177 ENSECAG00000009711)/27,871 (NCBI accession number 100052029) (Fig. 1B).

178

179 Amino acid sequence alignment

180 In PACRG, the G/A substitution resulted in replacement of valine (V) for methionine (M) at 181 position 182 (Fig. 2A). PACRG sequence alignment of wild type (WT) and altered proteins

182 predicted changes from beta-strand to alpha-helix structure in the altered protein a few amino 183 acids distant from the site of substitution (182) at positions 187 and 188 (Fig. 2B).

184 Hydrophobicity and isoelectric point were expected to remain similar despite the substitution 185 (Geneious). In the RTTN sequence alignment, T/A substitution resulted in replacement of 186 arginine (R) with tryptophan (W) at position 1807 of the ENSECAT00000010304 protein 187 isoform (Ensembl sequence, corresponding to position 1812 of isoform X1 in NCBI 188 [XP_001493238]) in NCBI sequence) (Fig. 3A). Sequence alignment of WT and altered proteins 189 indicated a change from alpha helix to beta strand structure near the site of substitution (bp 190 1,807) at position 1,816 (Fig. 3B). In addition, increased hydrophobicity and decreased pI were 191 projected at the site of substitution $(1,807)$ in the altered compared to the WT protein. 
192

\section{Expression of $P A C R G$ and $R T T N$}

194 Counts per million (cpm) for PACRG ranged from 30.7 to 66.3 (mean $=44.17$ ) in asthmatic 195 horses (Fig. 4A) and 25.1 to 65.6 (mean = 39.31) in non-asthmatic horses (Fig. 4B), while 196 expression of $R T T N$ varied from $\sim 11.5$ to 24.9 (mean $=17.61)$ and $\sim 13.1$ to $29.9($ mean $=21.46)$ 197 in asthmatic (Fig. 4C) and non-asthmatic (Fig. 4D) horses, respectively.

198

199 Confirmation of RNA-Seq with DNA Sanger sequencing

200 The PACRG substitution variants identified by RNA-Seq were confirmed on DNA with Sanger 201 sequencing of PCR amplicons in 10 asthmatic (Fig. 5A) and 14 non-asthmatic (Fig. 5B) horses. 202 In the asthmatic group, four horses were heterozygous $[\mathrm{A} / \mathrm{G}]$ and two were homozygous with 203 altered alleles [A/A] (Fig. 5A). In the non-asthmatic group, one horse was heterozygous with 204 alleles $[\mathrm{A} / \mathrm{G}]$, three horses were homozygous-WT [G/G] and three horses were homozygous205 altered [A/A] (Fig. 5B). DNA was not available to confirm the genotype of horse 1. Hence, all 206 genotypes derived from RNA-Seq were identical to Sanger sequencing results.

For RTTN, results of RNA-Seq and Sanger sequencing were very similar (Fig. 6). Four 208 asthmatic horses were heterozygous $[\mathrm{A} / \mathrm{T}]$ and two were homozygous altered [A/A] (Fig. 6A). In 209 the non-asthmatic group, horse 5 was heterozygous [A/T] and four horses were identified as 210 homozygous WT [T/T]. However, horse 1 was identified as homozygous before and

211 heterozygous after the asthmatic challenge, while horse 4 was identified as heterozygous before 212 and homozygous after the asthmatic challenge. Based on Sanger sequencing the genotype of 213 horse 4 was homozygous. DNA was not available to confirm the genotype of horse 1. In all 214 asthmatic horses, genotypes were consistent between pre- and post-challenge and sequencing 215 methods.

216

\section{Sequence alignment}

218 Sanger DNA sequences of $P A C R G$ from 10 asthmatic horses and 14 non-asthmatic horses 219 (including those that were analyzed by RNA-Seq) were aligned. Among asthmatic horses, eight 220 had the heterozygous $[\mathrm{A} / \mathrm{G}]$, two had the homozygous altered $[\mathrm{A} / \mathrm{A}]$ and none had the

221 homozygous WT [G/G] genotype. Among non-asthmatic horses, six had the heterozygous [A/G], 222 five had the homozygous altered $[\mathrm{A} / \mathrm{A}]$ and three had the homozygous WT $[\mathrm{G} / \mathrm{G}]$ genotype (Fig. 
223 7A). RTTN alignment in asthmatic horses yielded five heterozygous [A/T], two homozygous

224 altered [A/A], and three homozygous WT [T/T] genotypes. In non-asthmatic horses, four had the

225 heterozygous [A/T], 10 had the homozygous-WT [T/T], and no horse had the homozygous

226 altered [A/A] genotype (Fig. 7B).

227

228 DISCUSSION

229 The goal of this study was to assess the reliability of an adapted RNA-Seq sequence variant 230 calling workflow compared to Sanger sequencing. Sequence variant calling using RNA-Seq 231 reads is recent practice, and reliability of results is a function of sequencing platform, depth, 232 quality, precision of read mapping, and appropriate sequence variant calling and filtering 233 methods. The reliability of identifying gene sequence variants using RNA-Seq has been 234 considered uncertain. In some reports RNA-Seq was considered useful for identifying gene 235 variants $[54,55]$ while in other reports differences between RNA and DNA sequences were 236 relatively frequent [56-58].

237 In this study we applied a modification of GATK best practices for sequence variant 238 calling with RNA-Seq, and verified the results with Sanger sequencing. In 24 of 26 samples substitution variants in PACRG and RTTN were identified by both methods, while two horses' genotypes were discordant by RNA-Seq with inconsistent genotypes before and after challenge.

241 Sanger sequencing confirmed one of the discordant genotypes, while the other could not be 242 further assessed.

243 Two candidate substitution variants in the $P A C R G$ and $R T T N$ coding sequence were 244 identified after stringent filtering. Presence of the substitution variants was confirmed with PCR 245 and Sanger sequencing in 24 samples. Correlation between RNA-Seq and Sanger sequencing 246 showed that for $P A C R G$ both alleles of the gene were properly identified in all horses and 247 conditions by the modified GATK workflow. For RTTN, two of the samples were misidentified 248 by the workflow with alleles inconsistently identified before and after challenge. Lower mean 249 expression suggesting lower sequencing coverage for RTTN might have affected the likelihood 250 of inaccurate sequence variant calling. Nonetheless, the vast majority of alleles were identified 251 appropriately, suggesting that the workflow is suitable for sequence variant calling in RNA-Seq 252 at gene coverage in the 10 to $20 \mathrm{cpm}$ range. 
253 For supplementary analysis, SIFT was initially applied, followed by PolyPhen2 and

254 SNAP2, to predict sequence variant effects on protein function for both substitution variants.

255 SIFT uses phylogenetic data [45-49], while PolyPhen2 uses structural information and multiple

256 alignments [50] to predict whether or not a sequence variant may cause loss of function. The two

257 methods often yield similar results, but limited specificity suggests that results should be

258 interpreted with caution [59]. SNAP2, on the other hand, uses evolutionary, structural, solvent-

259 access and annotation information, as well as data from available homologs to predict whether a

260 sequence variant is likely to have an effect on protein function [51-53]. While these three

261 approaches can yield different results [60,61], inferences regarding PACRG and RTTN amino

262 acid substitutions were consistent. However, ultimately conclusions regarding the effect of

263 substitution variants require stringent protein functional analysis, and results from this study

264 should be considered preliminary.

265 The substitutions identified changed V182M (valine to methionine) and R1807W

266 (arginine to tryptophan) in PACRG and RTTN, respectively. For PACRG, the V->M

267 substitution minimally affected hydrophobicity and pI, while the R->W substitution in RTTN

268 increased hydrophobicity and decreased $\mathrm{pI}$. The substitution variants were considered to

269 potentially cause loss of function and to have non-neutral effects (Suppl. Tables 1 and 2).

$270 P A C R G$ is a gene conserved across species [62] that shares a bi-directional promoter with parkin

271 (PARK2) [63]. PACRG is affiliated with axonemal doublet microtubules, and contributes to the

272 signaling pathway that controls dynein-driven microtubule sliding [62,64-66]. A single

273 nucleotide variant (SNV) in $P A C R G$ was strongly associated with an increased risk of

274 developing childhood asthma following early-life tobacco smoke exposure [67].

275 For the RTTN substitution variant, tryptophan is an aromatic, non-polar and hydrophobic

276 amino acid often buried in hydrophobic cores, while arginine is a polar and positively charged

277 amino acid often found on outside chains [68]. RTTN is a cilium-associated protein [69]

278 essential for assembly of centrosomes in non-motile and motile cilia [70]. Absence of RTTN, or

279 presence of gene sequence variants that disrupt the interaction of RTTN with SCL/TAL1

280 interrupting locus (STIL), abrogate proper ciliary development and function [70], and recessive

281 mutations in RTTN are linked to abnormal primary ciliary development in humans [71]. A

282 change in the structural stability or binding affinity of the entire protein or the affected residue

283 could impact ciliary structure and function. The R1807W substitution variant in the carboxy- 
284 terminal region is not immediately proximal to the suggested centrosome-targeting and STIL-

285 binding site [70] but could nevertheless result in defective centrioles and hence affect cilium 286 structure and function.

287 Substitution variant sequence determination in 13 RNA-Seq and 11 additional samples

288 showed that $80 \%$ of asthmatic animals were heterozygous and $20 \%$ were homozygous-altered for

289 PACRG, and that no individual had the homozygous-WT genotype (G/G). Conversely, among

290 non-asthmatic animals more than half were homozygous, whether WT or altered (5 [A/A] and 3

291 [G/G]). For RTTN, 20\% of asthmatic horses were homozygous-altered (A/A), 30\% were

292 homozygous WT (T/T) and 50\% were heterozygous. Among non-asthmatics, none was

293 homozygous altered (A/A), while 71\% of horses were homozygous WT (T/T) and 29\% were

294 heterozygous. Therefore, the substitution was present in $70 \%$ of asthmatic horses and in only

$29530 \%$ of non-asthmatic horses (heterozygous or homozygous altered). Albeit, the variants have

296 been identified in only a small sample of asthmatic and non-asthmatic animals, and have to be

297 considered as variants of unknown significance (VUS). A comprehensive genome-wide

298 association study (GWAS) would be necessary to determine association between these VUS and

299 asthma, and statistical analysis of potential associations would need to be performed prior to

300 filtering of variants.

301 Pearson's Chi-squared test with Yates' continuity correction applied detected no

302 difference in allele frequency for $P A C R G$, or in genotype frequency for RTTN and $P A C R G$,

303 between asthmatic and non-asthmatic horses. A significantly higher frequency of the altered

304 allele (A) in asthmatic compared to non-asthmatic horses was identified. For PACRG, although

305 not significant, the $p$-value obtained after testing for differences in genotype frequency $(P=$

306 0.213) was lower than when testing for allele frequency $(P=1)$. This finding may be attributed

307 to the higher proportion of asthmatic horses with a heterogeneous genotype (WT/alt for eight of

308 ten horses) compared to non-asthmatics (WT/alt for six of 14 horses). However, changes in allele

309 frequency and potential roles in the pathogenesis of asthma are of unknown significance due to

310 the small sample size in this study. Notwithstanding, a significant difference in the frequency of

311 the $P A C R G$ heterozygous genotype has been reported in pulmonary tuberculosis in humans [72].

312 A genome-wide interaction study also identified a PACRG SNP to be linked to an increased risk

313 of developing childhood-onset asthma following early-life exposure to tobacco smoke [67].

314 SNPs in $P A C R G$ also contributed to susceptibility to tuberculosis [73]. 
For RTTN, the difference in allele frequency was encouraging and further analysis with a

316 larger number of samples to assess association with asthma may be warranted. RTTN is a

317 centrosome-associated protein first discovered for its role in axial rotation and left-right

318 specification in the mouse embryo [69]. The R->W substitution altered the hydrophobicity and

319 isoelectric point at position 1807 , and $\mathrm{R}<=>\mathrm{W}$ substitutions were predicted to be most

320 problematic in the human genome [74]. In addition, R->W substitution is generally disfavored in

321 all protein types [75]. Overrepresentation of mutated arginine was a prominent feature among

322 disease-causing mutations in a range of conditions [76].

323 As landmarks in epithelial-environmental interaction, cilia are highly specialized cellular

324 projections. Most vertebrate cells have a single non-motile ('primary') cilium that transduces

325 signals from the environment or other cells, while motile cilia occur in multiples on specialized

326 cells of the respiratory tract, oviduct and ventricles of the brain [77,78]. Motile cilia directionally

327 propel cells or extracellular fluid through "metachronal wave" beating movements $[79,80]$. The

328 ability of motile cilia to beat in a synchronized manner requires specialized proteins that are

329 absent in non-motile primary cilia, but otherwise both types of cilia have similar internal

330 architecture. The main part of the cilium is the axoneme, which is comprised of nine outer

331 microtubule doublets, one central microtubule pair (in motile multiple cilia) and a multitude of

332 affiliated proteins. Prominent among these are tektins that stabilize microtubules and regulate

333 axoneme length [81], and protofilament ribbon proteins that are essential for sliding of adjacent

334 microtubule doublets to generate ciliary movement [82]. Abnormalities in cilia are now

335 appreciated as cause for the development of respiratory diseases, often through gene sequence

336 variants associated with a loss of function affecting unique ciliary proteins [77]. Ultrastructural

337 changes were previously reported in the ciliated epithelium of horses with severe asthma

338 (formerly called chronic obstructive pulmonary disease [COPD]), and included loss of ciliated

339 cells [83]. Factors that affect beating, synchronization or orientation of motile cilia result in

340 accumulation of mucus in airways [77], which is a prominent feature of equine asthma.

341 Furthermore, hedgehog $(\mathrm{HH})$ signaling is strongly linked to ciliary function, and many

342 components of the HH signaling pathway localize to cilia [84,85]. However, considering the

343 relatively small number of individuals tested, allele frequencies identified in this manuscript, and

344 their potential impact on ciliary function, remain to be confirmed on a larger scale. 
PACRG may be linked to HH signaling in mice where patched1 (PTCH1) and PACRG-

$346 P A R K 2$ loci are thought to interact and regulate ciliary function in ependymal cells [86].

347 Interestingly, $P T C H 1$ is differentially expressed in asthmatic compared to non-asthmatic horses

348 following challenge [39], linking $P A C R G$ and an asthmatic response to environmental agents

349 with the HH pathway. The PACRG protein associates with protofilaments [87] of the ciliary

350 axoneme [62,88,89], has a role in ciliary morphogenesis and function [65] and is directly

351 involved in ciliary motility through control of dynein-driven microtubule sliding [64]. PACRG

352 also has a variety of interacting partners such as microtubules, $\alpha$ - and $\beta$-tubulin and

353 meiosis/spermiogenesis associated 1 (MEIG1) protein, heat shock protein (HSP) 70 and HSP 90

$354[66,90,91]$. Impaired function or interaction of PACRG with its partners could weaken or impair 355 ciliary stability and motility. The exact nature and function of methionine in protein structure 356 remains incompletely understood, and substitutions involving methionine has been associated 357 with several diseases [92]. Both valine and methionine are hydrophobic residues grouped among 358 the least polar amino acids [93]. Methionine is a sulfur-containing amino acid that is among the 359 most hydrophobic residues and also easily oxidized if exposed [94]. Although $\mathrm{V}->\mathrm{M}$

360 substitutions are generally neutral, methionine's sulfur connected to a methyl group would make 361 it less likely to interact with other proteins [75]. Methionine was overrepresented as a mutant 362 residue in several mutations associated with decrease or loss of function [76], including the 363 human androgen receptor [95]. Although the effect of a V->M substitution is unknown, any 364 change in PACRG structure or binding affinity could impact ciliary function, and may be of 365 great interest in the context of severe asthma.

\section{CONCLUSIONS}

369 Sequence variants can be confidently called with RNA-Seq, although the required minimal 370 coverage remains to be clearly defined and may be variable. Single point substitution variants in $371 P A C R G$ and RTTN were detected in all asthmatic horses, and although there was no significant 372 difference in allele and genotype proportions between the two groups, the altered allele in the 373 RTTN gene was more prevalent in asthmatic compared to non-asthmatic horses. Functional cilia 374 are crucial for lung health, and sequence variants resulting in impaired protein function are likely 
375 to have a negative impact. The significance of the substitutions in $P A C R G$ and $R T T N$ remains to

376 be determined but they are of potential interest for future investigations.

377

378 ACKNOWLEDGEMENTS

379 The authors thank Laurent Viel, Mary Ellen Clark and Andrés Diaz-Méndez for assistance with 380 animal handling, biopsy collection and respiratory function measurements.

381

382

\section{REFERENCES}

383

384

385

1. Couëtil LL, Cardwell JM, Gerber V, Lavoie J-P, Léguillette R, Richard EA. Inflammatory

386 Airway Disease of Horses--Revised Consensus Statement. J Vet Intern Med. 2016;30:503-15.

2. Pirie RS. Recurrent airway obstruction: a review. Equine Vet J. 2014;46:276-88.

388

3. Martinez FD, Vercelli D. Asthma. Lancet. 2013;382:1360-72.

389

4. Vargas A, Roux-Dalvai F, Droit A, Lavoie J-P. Neutrophil-Derived Exosomes: A New

Mechanism Contributing to Airway Smooth Muscle Remodeling. Am J Respir Cell Mol Biol.

390 2016;55:450-61.

5. Setlakwe EL, Lemos KR, Lavoie-Lamoureux A, Duguay J-D, Lavoie J-P. Airway collagen

392 and elastic fiber content correlates with lung function in equine heaves. Am J Physiol Lung Cell Mol Physiol. 2014;307:L252-60.

6. Wenzel SE. Asthma phenotypes: the evolution from clinical to molecular approaches. Nat 395 Med. 2012;18:716-25.

7. Skloot GS. Asthma phenotypes and endotypes: a personalized approach to treatment. Curr Opin Pulm Med. 2016;22:3-9.

8. Ilmarinen P, Tuomisto LE, Kankaanranta H. Phenotypes, Risk Factors, and Mechanisms of Adult-Onset Asthma. Mediators Inflamm. 2015;2015:514868.

9. Lavoie JP, Maghni K, Desnoyers M, Taha R, Martin JG, Hamid QA. Neutrophilic airway inflammation in horses with heaves is characterized by a Th2-type cytokine profile. Am J Respir

402 Crit Care Med. 2001;164:1410-3.

403 10. Joubert P, Silversides DW, Lavoie JP. Equine neutrophils express mRNA for tumour 404 necrosis factor-alpha, interleukin (IL)-1beta, IL-6, IL-8, macrophage-inflammatory-protein-2 but 405 not for IL-4, IL-5 and interferon-gamma. Equine Vet J. 2001;33:730-3. 
406 11. Klukowska-Rötzler J, Marti E, Lavoie J-P, Ainsworth DM, Gerber V, Zurbriggen A, Janda J. 407 Expression of thymic stromal lymphopoietin in equine recurrent airway obstruction. Vet 408 Immunol Immunopathol. 2012;146:46-52.

409 12. Ainsworth DM, Grünig G, Matychak MB, Young J, Wagner B, Erb HN, Antczak DF. 410 Recurrent airway obstruction (RAO) in horses is characterized by IFN-gamma and IL-8 411 production in bronchoalveolar lavage cells. Vet Immunol Immunopathol. 2003;96:83-91.

412 13. Debrue M, Hamilton E, Joubert P, Lajoie-Kadoch S, Lavoie J-P. Chronic exacerbation of 413 equine heaves is associated with an increased expression of interleukin-17 mRNA in 414 bronchoalveolar lavage cells. Vet Immunol Immunopathol. 2005;105:25-31.

415 14. Ainsworth DM, Matychak M, Reyner CL, Erb HN, Young JC. Effects of in vitro exposure to 416 hay dust on the gene expression of chemokines and cell-surface receptors in primary bronchial 417 epithelial cell cultures established from horses with chronic recurrent airway obstruction. Am J 418 Vet Res. 2009;70:365-72.

419 15. Ainsworth DM, Wagner B, Erb HN, Young JC, Retallick DE. Effects of in vitro exposure to 420 hay dust on expression of interleukin-17,-23,-8, and-1 $\beta$ and chemokine (CXC motif) ligand 2 by 421 pulmonary mononuclear cells isolated from horses chronically affected with recurrent airway 422 disease. Am J Vet Res. 2007;68:1361-9.

423 16. Lavoie-Lamoureux A, Moran K, Beauchamp G, Mauel S, Steinbach F, Lefebvre-Lavoie J, 424 Martin JG, Lavoie J-P. IL-4 activates equine neutrophils and induces a mixed inflammatory 425 cytokine expression profile with enhanced neutrophil chemotactic mediator release ex vivo. Am 426 J Physiol Lung Cell Mol Physiol. 2010;299:L472-82.

427 17. Padoan E, Ferraresso S, Pegolo S, Castagnaro M, Barnini C, Bargelloni L. Real time RT428 PCR analysis of inflammatory mediator expression in recurrent airway obstruction-affected 429 horses. Vet Immunol Immunopathol. 2013;156:190-9.

430 18. Marti E, Gerber H, Essich G, Oulehla J, Lazary S. The genetic basis of equine allergic 431 diseases 1. Chronic hypersensitivity bronchitis. Equine Vet J. 1991;23:457-60.

432 19. Couëtil LL, Ward MP. Analysis of risk factors for recurrent airway obstruction in North 433 American horses: 1,444 cases (1990-1999). J Am Vet Med Assoc. 2003;223:1645-50.

434 20. Ramseyer A, Gaillard C, Burger D, Straub R, Jost U, Boog C, Marti E, Gerber V. Effects of 435 genetic and environmental factors on chronic lower airway disease in horses. Journal of 436 veterinary internal medicine. 2007;21:149-56. 
437 21. Moffatt MF, Kabesch M, Liang L, Dixon AL, Strachan D, Heath S, Depner M, von Berg A, 438 Bufe A, Rietschel E, Heinzmann A, Simma B, Frischer T, Willis-Owen SAG, Wong KCC, Illig 439 T, Vogelberg C, Weiland SK, von Mutius E, Abecasis GR, Farrall M, Gut IG, Lathrop GM, 440 Cookson WOC. Genetic variants regulating ORMDL3 expression contribute to the risk of 441 childhood asthma. Nature. 2007;448:470-3.

442 22. Choudhry S, Taub M, Mei R, Rodriguez-Santana J, Rodriguez-Cintron W, Shriver MD, Ziv 443 E, Risch NJ, Burchard EG. Genome-wide screen for asthma in Puerto Ricans: evidence for 444 association with 5q23 region. Hum Genet. 2008;123:455-68.

445 23. Galanter J, Choudhry S, Eng C, Nazario S, Rodríguez-Santana JR, Casal J, Torres-Palacios 446 A, Salas J, Chapela R, Watson HG, Meade K, LeNoir M, Rodríguez-Cintrón W, Avila PC, 447 Burchard EG. ORMDL3 gene is associated with asthma in three ethnically diverse populations. 448 Am J Respir Crit Care Med. 2008;177:1194-200.

449 24. Tavendale R, Macgregor DF, Mukhopadhyay S, Palmer CNA. A polymorphism controlling 450 ORMDL3 expression is associated with asthma that is poorly controlled by current medications. 451 J Allergy Clin Immunol. 2008;121:860-3.

452 25. Madore A-M, Tremblay K, Hudson TJ, Laprise C. Replication of an association between 453 17q21 SNPs and asthma in a French-Canadian familial collection. Human genetics.

$454 \quad 2008 ; 123: 93-5$.

455 26. Hancock DB, Romieu I, Shi M, Sienra-Monge J-J, Wu H, Chiu GY, Li H, del Rio-Navarro 456 BE, Willis-Owen SAG, Willis-Owens SAG, Weiss ST, Raby BA, Gao H, Eng C, Chapela R, 457 Burchard EG, Tang H, Sullivan PF, London SJ. Genome-wide association study implicates 458 chromosome 9q21.31 as a susceptibility locus for asthma in mexican children. PLoS Genet. 459 2009;5:e1000623.

460 27. Himes BE, Hunninghake GM, Baurley JW, Rafaels NM, Sleiman P, Strachan DP, Wilk JB, 461 Willis-Owen SAG, Klanderman B, Lasky-Su J, Lazarus R, Murphy AJ, Soto-Quiros ME, Avila 462 L, Beaty T, Mathias RA, Ruczinski I, Barnes KC, Celedón JC, Cookson WOC, Gauderman WJ, 463 Gilliland FD, Hakonarson H, Lange C, Moffatt MF, O'Connor GT, Raby BA, Silverman EK, 464 Weiss ST. Genome-wide association analysis identifies PDE4D as an asthma-susceptibility gene. 465 Am J Hum Genet. 2009;84:581-93. 
466 28. Bisgaard H, Bønnelykke K, Sleiman PM, Brasholt M, Chawes B, Kreiner-Møller E, Stage M, 467 Kim C, Tavendale R, Baty F. Chromosome 17q21 gene variants are associated with asthma and 468 exacerbations but not atopy in early childhood. Am J Respir Crit Care Med. 2009; 179:179-85.

469 29. Wu H, Romieu I, Sienra-Monge J-J, Li H, del Rio-Navarro BE, London SJ. Genetic variation 470 in ORM1-like 3 (ORMDL3) and gasdermin-like (GSDML) and childhood asthma. Allergy. $4712009 ; 64: 629-35$.

472 30. Li X, Howard TD, Zheng SL, Haselkorn T, Peters SP, Meyers DA, Bleecker ER. Genome473 wide association study of asthma identifies RAD50-IL13 and HLA-DR/DQ regions. J Allergy 474 Clin Immunol. 2010;125:328-335.e11.

475 31. Sleiman PMA, Flory J, Imielinski M, Bradfield JP, Annaiah K, Willis-Owen SAG, Wang K, 476 Rafaels NM, Michel S, Bonnelykke K, Zhang H, Kim CE, Frackelton EC, Glessner JT, Hou C, 477 Otieno FG, Santa E, Thomas K, Smith RM, Glaberson WR, Garris M, Chiavacci RM, Beaty TH, 478 Ruczinski I, Orange JS, Orange JM, Allen J, Spergel JM, Grundmeier R, Mathias RA, Christie 479 JD, von Mutius E, Cookson WOC, Kabesch M, Moffatt MF, Grunstein MM, Barnes KC, Devoto 480 M, Magnusson M, Li H, Grant SFA, Bisgaard H, Hakonarson H. Variants of DENND1B 481 associated with asthma in children. N Engl J Med. 2010;362:36-44.

482 32. Moffatt MF, Gut IG, Demenais F, Strachan DP, Bouzigon E, Heath S, von Mutius E, Farrall 483 M, Lathrop M, Cookson WOCM. A large-scale, consortium-based genomewide association 484 study of asthma. N Engl J Med. 2010;363:1211-21.

485 33. Ferreira MA, Matheson MC, Duffy DL, Marks GB, Hui J, Le Souëf P, Danoy P, Baltic S, 486 Nyholt DR, Jenkins M. Identification of IL6R and chromosome 11q13. 5 as risk loci for asthma. 487 The Lancet. 2011;378:1006-14.

488 34. Torgerson DG, Ampleford EJ, Chiu GY, Gauderman WJ, Gignoux CR, Graves PE, Himes 489 BE, Levin AM, Mathias RA, Hancock DB, Baurley JW, Eng C, Stern DA, Celedón JC, Rafaels 490 N, Capurso D, Conti DV, Roth LA, Soto-Quiros M, Togias A, Li X, Myers RA, Romieu I, Van 491 Den Berg DJ, Hu D, Hansel NN, Hernandez RD, Israel E, Salam MT, Galanter J, Avila PC, 492 Avila L, Rodriquez-Santana JR, Chapela R, Rodriguez-Cintron W, Diette GB, Adkinson NF, 493 Abel RA, Ross KD, Shi M, Faruque MU, Dunston GM, Watson HR, Mantese VJ, Ezurum SC, 494 Liang L, Ruczinski I, Ford JG, Huntsman S, Chung KF, Vora H, Li X, Calhoun WJ, Castro M, 495 Sienra-Monge JJ, del Rio-Navarro B, Deichmann KA, Heinzmann A, Wenzel SE, Busse WW, 496 Gern JE, Lemanske RF, Beaty TH, Bleecker ER, Raby BA, Meyers DA, London SJ, Gilliland 
497 FD, Burchard EG, Martinez FD, Weiss ST, Williams LK, Barnes KC, Ober C, Nicolae DL.

498 Meta-analysis of genome-wide association studies of asthma in ethnically diverse North 499 American populations. Nat Genet. 2011;43:887-92.

500 35. Swinburne JE, Bogle H, Klukowska-Rötzler J, Drögemüller M, Leeb T, Temperton E, Dolf

501 G, Gerber V. A whole-genome scan for recurrent airway obstruction in Warmblood sport horses 502 indicates two positional candidate regions. Mamm Genome. 2009;20:504-15.

503 36. Klukowska-Rötzler J, Swinburne JE, Drögemüller C, Dolf G, Janda J, Leeb T, Gerber V. The 504 interleukin 4 receptor gene and its role in recurrent airway obstruction in Swiss Warmblood 505 horses. Anim Genet. 2012;43:450-3.

506 37. Jost U, Klukowska-Rötzler J, Dolf G, Swinburne JE, Ramseyer A, Bugno M, Burger D, Blott

$507 \mathrm{~S}$, Gerber V. A region on equine chromosome 13 is linked to recurrent airway obstruction in 508 horses. Equine Vet J. 2007;39:236-41.

509 38. Klukowska-Rötzler J, Gerber V, Leeb T. Association analysis of SNPs in the IL21R gene 510 with recurrent airway obstruction (RAO) in Swiss Warmblood horses. Anim Genet.

$5112012 ; 43: 475-6$.

512 39. Tessier L, Côté O, Clark ME, Viel L, Diaz-Méndez A, Anders S, Bienzle D. Impaired

513 response of the bronchial epithelium to inflammation characterizes severe equine asthma. BMC

514 Genomics. 2017;18:708.

515 40. Wade CM, Giulotto E, Sigurdsson S, Zoli M, Gnerre S, Imsland F, Lear TL, Adelson DL,

516 Bailey E, Bellone RR. Genome sequence, comparative analysis, and population genetics of the 517 domestic horse. Science. 2009;326:865-7.

518 41. Dobin A, Davis CA, Schlesinger F, Drenkow J, Zaleski C, Jha S, Batut P, Chaisson M, 519 Gingeras TR. STAR: ultrafast universal RNA-seq aligner. Bioinformatics. 2013;29:15-21.

520 42. McKenna A, Hanna M, Banks E, Sivachenko A, Cibulskis K, Kernytsky A, Garimella K, 521 Altshuler D, Gabriel S, Daly M, DePristo MA. The Genome Analysis Toolkit: a MapReduce 522 framework for analyzing next-generation DNA sequencing data. Genome Res. 2010;20:1297523303.

524 43. Guo Y, Ding X, Shen Y, Lyon GJ, Wang K. SeqMule: automated pipeline for analysis of 525 human exome/genome sequencing data. Sci Rep. 2015;5:srep14283. 
526 44. McLaren W, Pritchard B, Rios D, Chen Y, Flicek P, Cunningham F. Deriving the

527 consequences of genomic variants with the Ensembl API and SNP Effect Predictor.

528 Bioinformatics. 2010;26:2069-70.

529 45. Ng PC, Henikoff S. Predicting deleterious amino acid substitutions. Genome Res.

$530 \quad 2001 ; 11: 863-74$.

531 46. Ng PC, Henikoff S. Accounting for human polymorphisms predicted to affect protein

532 function. Genome Res. 2002;12:436-46.

533 47. Ng PC, Henikoff S. SIFT: Predicting amino acid changes that affect protein function. Nucleic 534 Acids Res. 2003;31:3812-4.

535 48. Ng PC, Henikoff S. Predicting the effects of amino acid substitutions on protein function.

536 Annu Rev Genomics Hum Genet. 2006;7:61-80.

537 49. Kumar P, Henikoff S, Ng PC. Predicting the effects of coding non-synonymous variants on

538 protein function using the SIFT algorithm. Nat Protoc. 2009;4:1073-81.

539 50. Adzhubei I, Jordan DM, Sunyaev SR. Predicting functional effect of human missense

540 mutations using PolyPhen-2. Curr Protoc Hum Genet. 2013; Chapter 7:Unit7.20.

541 51. Hecht M, Bromberg Y, Rost B. News from the protein mutability landscape. J Mol Biol.

$542 \quad 2013 ; 425: 3937-48$.

543 52. Bromberg Y, Rost B. SNAP: predict effect of non-synonymous polymorphisms on function.

544 Nucleic Acids Res. 2007;35:3823-35.

545 53. Hecht M, Bromberg Y, Rost B. Better prediction of functional effects for sequence variants.

546 BMC Genomics. 2015;16 Suppl 8:S1.

547 54. Quinn EM, Cormican P, Kenny EM, Hill M, Anney R, Gill M, Corvin AP, Morris DW.

548 Development of strategies for SNP detection in RNA-seq data: application to lymphoblastoid

549 cell lines and evaluation using 1000 Genomes data. PLoS One. 2013;8:e58815.

550 55. Piskol R, Ramaswami G, Li JB. Reliable identification of genomic variants from RNA-seq

551 data. Am J Hum Genet. 2013;93:641-51.

552 56. Sheng Q, Zhao S, Li C-I, Shyr Y, Guo Y. Practicability of detecting somatic point mutation 553 from RNA high throughput sequencing data. Genomics. 2016;107:163-9.

554 57. Guo Y, Zhao S, Sheng Q, Samuels DC, Shyr Y. The discrepancy among single nucleotide

555 variants detected by DNA and RNA high throughput sequencing data. BMC Genomics.

$5562017 ; 18: 690$. 
557 58. Li X, Howard TD, Moore WC, Ampleford EJ, Li H, Busse WW, Calhoun WJ, Castro M, 558 Chung KF, Erzurum SC, Fitzpatrick AM, Gaston B, Israel E, Jarjour NN, Teague WG, Wenzel

559 SE, Peters SP, Hawkins GA, Bleecker ER, Meyers DA. Importance of hedgehog interacting 560 protein and other lung function genes in asthma. J Allergy Clin Immunol. 2011;127:1457-65.

561 59. Flanagan SE, Patch A-M, Ellard S. Using SIFT and PolyPhen to predict loss-of-function and 562 gain-of-function mutations. Genet Test Mol Biomarkers. 2010;14:533-7.

563 60. Dong C, Wei P, Jian X, Gibbs R, Boerwinkle E, Wang K, Liu X. Comparison and integration 564 of deleteriousness prediction methods for nonsynonymous SNVs in whole exome sequencing 565 studies. Hum Mol Genet. 2015;24:2125-37.

566 61. Thusberg J, Vihinen M. Pathogenic or not? And if so, then how? Studying the effects of 567 missense mutations using bioinformatics methods. Hum Mutat. 2009;30:703-14.

568 62. Thumberger T, Hagenlocher C, Tisler M, Beyer T, Tietze N, Schweickert A, Feistel K, Blum

569 M. Ciliary and non-ciliary expression and function of PACRG during vertebrate development.

570 Cilia. 2012;1:13.

571 63. West AB, Lockhart PJ, O'Farell C, Farrer MJ. Identification of a novel gene linked to parkin 572 via a bi-directional promoter. J Mol Biol. 2003;326:11-9.

573 64. Mizuno K, Dymek EE, Smith EF. Microtubule binding protein PACRG plays a role in 574 regulating specific ciliary dyneins during microtubule sliding. Cytoskeleton. 2016;73:703-11.

575 65. Wilson GR, Wang HX, Egan GF, Robinson PJ, Delatycki MB, O'Bryan MK, Lockhart PJ.

576 Deletion of the Parkin co-regulated gene causes defects in ependymal ciliary motility and

577 hydrocephalus in the quakingviable mutant mouse. Hum Mol Genet. 2010;19:1593-602.

578 66. Ikeda T. Parkin-co-regulated gene (PACRG) product interacts with tubulin and microtubules. 579 FEBS Lett. 2008;582:1413-8.

580 67. Scholtens S, Postma DS, Moffatt MF, Panasevich S, Granell R, Henderson AJ, Melén E, 581 Nyberg F, Pershagen G, Jarvis D, Ramasamy A, Wjst M, Svanes C, Bouzigon E, Demenais F, 582 Kauffmann F, Siroux V, von Mutius E, Ege MJ, Braun-Fahrländer C, Genuneit J, group GS, 583 Brunekreef B, Smit HA, Wijga AH, Kerkhof M, Curjuric I, Imboden M, Thun GA, Probst584 Hensch N, Freidin MB, Bragina EI, Deev IA, Puzyrev VP, Daley D, Park J, Becker A, Chan585 Yeung M, Kozyrskyj AL, Pare P, Marenholz I, Lau S, Keil T, Lee Y-A, Kabesch M, Wijmenga 586 C, Franke L, Nolte IM, Vonk J, Kumar A, Farrall M, Cookson WO, Strachan DP, Koppelman 
587 GH, Boezen HM. Novel childhood asthma genes interact with in utero and early-life tobacco 588 smoke exposure(). J Allergy Clin Immunol. 2014;133:885-8.

589 68. Betts MJ, Russell RB. Amino Acid Properties and Consequences of Substitutions. In:

590 Bioinformatics for Geneticists. John Wiley \& Sons, Ltd; 2003. p. 289-316.

591 69. Faisst AM, Alvarez-Bolado G, Treichel D, Gruss P. Rotatin is a novel gene required for axial

592 rotation and left-right specification in mouse embryos. Mech Dev. 2002;113:15-28.

593 70. Chen H-Y, Wu C-T, Tang C-JC, Lin Y-N, Wang W-J, Tang TK. Human microcephaly

594 protein RTTN interacts with STIL and is required to build full-length centrioles. Nat Commun. $5952017 ; 8: 247$.

596 71. Kheradmand Kia S, Verbeek E, Engelen E, Schot R, Poot RA, de Coo IFM, Lequin MH, 597 Poulton CJ, Pourfarzad F, Grosveld FG, Brehm A, de Wit MCY, Oegema R, Dobyns WB,

598 Verheijen FW, Mancini GMS. RTTN mutations link primary cilia function to organization of the 599 human cerebral cortex. Am J Hum Genet. 2012;91:533-40.

600 72. Udina IG, Kordicheva SI, Pospelov LE, Malenko AF, Gergert VI, Pospelov AL, Matrashkin 601 AG, Kyzyl-Ool MM, Nachin AA, Zhivotovskiı̌ LA. [Study of the polymorphic markers--the

602 PARK2 and PACRG genes due to the incidence of pulmonary tuberculosis in two districts of the 603 Republic of Tyva]. Probl Tuberk Bolezn Legk. 2007:27-9.

604 73. Bragina EY, Tiys ES, Rudko AA, Ivanisenko VA, Freidin MB. Novel tuberculosis

605 susceptibility candidate genes revealed by the reconstruction and analysis of associative 606 networks. Infect Genet Evol. 2016;46:118-23.

607 74. Majewski J, Ott J. Amino acid substitutions in the human genome: evolutionary implications 608 of single nucleotide polymorphisms. Gene. 2003;305:167-73.

609 75. Betts MJ, Russell RB. Amino acid properties and consequences of substitutions.

610 Bioinformatics for geneticists. 2003;317:289.

611 76. Khan S, Vihinen M. Spectrum of disease-causing mutations in protein secondary structures.

612 BMC Struct Biol. 2007;7:56.

613 77. Reiter JF, Leroux MR. Genes and molecular pathways underpinning ciliopathies. Nat Rev

614 Mol Cell Biol. 2017;18:533-47.

615 78. Szymanska K, Johnson CA. The transition zone: an essential functional compartment of cilia. 616 Cilia. 2012;1:10. 
617 79. Eshel D, Priel Z. Characterization of metachronal wave of beating cilia on frog's palate 618 epithelium in tissue culture. J Physiol. 1987;388:1-8.

619 80. Gheber L, Priel Z. On metachronism in ciliary systems: a model describing the dependence 620 of the metachronal wave properties on the intrinsic ciliary parameters. Cell Motil Cytoskeleton. 621 1990;16:167-81.

622 81. Steffen W, Linck RW. Evidence for tektins in centrioles and axonemal microtubules. Proc 623 Natl Acad Sci U S A. 1988;85:2643-7.

624 82. Linck RW, Norrander JM. Protofilament ribbon compartments of ciliary and flagellar 625 microtubules. Protist. 2003;154:299.

626 83. Kaup FJ, Drommer W, Deegen E. Ultrastructural findings in horses with chronic obstructive 627 pulmonary disease (COPD). I: Alterations of the larger conducting airways. Equine Vet J. 628 1990;22:343-8.

629 84. Huangfu D, Liu A, Rakeman AS, Murcia NS, Niswander L, Anderson KV. Hedgehog 630 signalling in the mouse requires intraflagellar transport proteins. Nature. 2003;426:83-7.

631 85. Goetz SC, Anderson KV. The primary cilium: a signalling centre during vertebrate 632 development. Nat Rev Genet. 2010;11:331-44.

633 86. Gavino C, Richard S. Patched1 haploinsufficiency impairs ependymal cilia function of the 634 quaking viable mice, leading to fatal hydrocephalus. Mol Cell Neurosci. 2011;47:100-7.

635 87. Ikeda K, Ikeda T, Morikawa K, Kamiya R. Axonemal localization of Chlamydomonas 636 PACRG, a homologue of the human Parkin-coregulated gene product. Cell Motil Cytoskeleton. 637 2007;64:814-21.

638 88. Lechtreck K-F, Luro S, Awata J, Witman GB. HA-tagging of putative flagellar proteins in 639 Chlamydomonas reinhardtii identifies a novel protein of intraflagellar transport complex B. Cell 640 Motil Cytoskeleton. 2009;66:469-82.

641 89. Dawe HR, Farr H, Portman N, Shaw MK, Gull K. The Parkin co-regulated gene product, 642 PACRG, is an evolutionarily conserved axonemal protein that functions in outer-doublet 643 microtubule morphogenesis. J Cell Sci. 2005;118:5421-30.

644 90. Li Y, Xiao X, Ji X, Liu B, Amos CI. RNA-seq analysis of lung adenocarcinomas reveals 645 different gene expression profiles between smoking and nonsmoking patients. Tumour Biol. $6462015 ; 36: 8993-9003$. 
647 91. Imai Y, Soda M, Murakami T, Shoji M, Abe K, Takahashi R. A product of the human gene 648 adjacent to parkin is a component of Lewy bodies and suppresses Pael receptor-induced cell 649 death. J Biol Chem. 2003;278:51901-10.

650 92. Valley CC, Cembran A, Perlmutter JD, Lewis AK, Labello NP, Gao J, Sachs JN. The 651 methionine-aromatic motif plays a unique role in stabilizing protein structure. Journal of 652 Biological Chemistry. 2012;287:34979-91.

653 93. Wolfenden R. Experimental measures of amino acid hydrophobicity and the topology of 654 transmembrane and globular proteins. J Gen Physiol. 2007;129:357-62.

655 94. Brosnan JT, Brosnan ME. The sulfur-containing amino acids: an overview. J Nutr. 656 2006;136:1636S-40S.

657 95. Kazemi-Esfarjani P, Beitel LK, Trifiro M, Kaufman M, Rennie P, Sheppard P, Matusik R, 658 Pinsky L. Substitution of valine- 865 by methionine or leucine in the human androgen receptor 659 causes complete or partial androgen insensitivity, respectively with distinct androgen receptor 660 phenotypes. Molecular Endocrinology. 1993;7:37-46.

661 


\section{LEGENDS}

663

664 Figure 1. Substitution variants in PACRG (A) and RTTN (B) genes. Diagrams show position of 665 gene (thick green line), mRNA (red line) and coding region (yellow line). Whole gene (upper) 666 and close-up view surrounding the substitution variant (lower) are included with gene sequence 667 at the bottom. Location of the substitution variant is indicated in blue for NCBI and Ensembl 668 databases.

669

670 Figure 2. Alignment of wild type (WT) and altered (alt) PACRG proteins with associated 671 predicted hydrophobicity and isoelectric point. Replacement of methionine for valine at position 672182 changes a beta strand to an alpha helix at position 187 and 188. Alpha helices (pink), coils 673 (gray line), turns (blue arrows) and beta strands (yellow arrows).

674

Figure 3. Alignment of WT and altered RTTN protein with predicted hydrophobicity and 676 isoelectric point. Replacement of arginine with tryptophan at position 1812 changes alpha helix to beta strand at position 1816. Alpha helices (pink), coils (gray line), turns (blue arrows) and 678 beta strands (yellow arrows).

679

680 681

Figure 4. Expression of PACRG (A, B) and RTTN (C, D) in asthmatic and non-asthmatic horses 682 in counts-per-million (CPM; y-axis) pre- and post-challenge. PACRG expression varied from $\sim 30.7$ to $66.3 \mathrm{CPM}$ in asthmatic horses (A) and 25.1 to $65.6 \mathrm{CPM}$ on non-asthmatic horses (B), 683 while RTTN expression varied from $\sim 11.5$ to 24.9 CPM and $\sim 13.1$ to 29.9 CPM in asthmatic (C) 684 and non-asthmatic (D) horses, respectively.

685

686 Figure 5. Comparison of GATK substitution variant calls and Sanger sequencing results for $687 P A C R G$ in asthmatic (A) and non-asthmatic (B) horses. For both groups, the bar graph indicates 688 the IGV count for each allele (A-red, G-yellow), horse and condition. Below the bar graph is the 689 GATK variant call, the electropherogram of the Sanger sequence, and agreement. (A) Four 690 asthmatic horses $(1,2,5,6)$ had heterozygous alleles $[\mathrm{A} / \mathrm{G}]$ and two (3 and 4) were homozygous 691 for the altered allele [A/A]. (B) In non-asthmatic horses, one horse (6) had heterozygous alleles $692[\mathrm{~A} / \mathrm{G}]$, three horses $(1,2$ and 4) were homozygous for the wild-type allele $[\mathrm{G} / \mathrm{G}]$ and three horses 
$693(3,5$ and 7$)$ were homozygous for the altered allele [A/A]. All genotypes were consistent across 694 horses and methods. DNA was not available for non-asthmatic horse 1.

695

696 Figure 6. Comparison of GATK substitution variant calls and Sanger sequencing results for 697 RTTN in asthmatic (A) and non-asthmatic (B) horses. Details as in Fig. 5. (A) Four asthmatic 698 horses (3-6) had heterozygous alleles $[\mathrm{A} / \mathrm{T}]$ and two (1 and 2) were homozygous for the altered 699 allele [A/A]. Genotypes were consistent across horses and methods. (B) In non-asthmatic horses, 700 one (5) had heterozygous [A/T] alleles, four horses had homozygous wild type [T/T] alleles, and 701 two horses (1 and 4) were inconsistently identified as homozygous wild type and heterozygous in 702 different samples. Sanger sequencing confirmed the genotype of horse 4 as heterozygous. DNA 703 was not available for non-asthmatic horse 1.

704

705 Figure 7. Alignment of PACRG (A) and RTTN (B) Sanger sequences for 10 asthmatic and 14 706 non-asthmatic horses with the reference genome. (A) For PACRG, 8 asthmatic horses (80\%) 707 were heterozygous $[\mathrm{A} / \mathrm{G}], 2(20 \%)$ were homozygous-altered $[\mathrm{A} / \mathrm{A}]$ and none was homozygous 708 wild-type $[\mathrm{G} / \mathrm{G}]$. Six non-asthmatic horses (43\%) were heterozygous $[\mathrm{A} / \mathrm{G}], 5(36 \%)$ were 709 homozygous-altered [A/A] and 3 (21\%) were homozygous wild type [G/G]. (B) For RTTN, in

710 the asthmatic group, there were $5(50 \%)$ heterozygous [A/T], $2(20 \%)$ homozygous-altered [A/A] 711 and 3 (30\%) homozygous wild type [T/T] genotypes. In the non-asthmatic group, 4 (29\%) were 712 heterozygous $[\mathrm{A} / \mathrm{G}], 10(71 \%)$ were homozygous wild type [T/T], and none had the 713 homozygous-altered $[\mathrm{A} / \mathrm{A}]$ genotype.

714 


\section{Figure 1}

Substitution variants in PACRG (A) and RTTN (B) genes.

Diagrams show position of gene (thick green line), mRNA (red line) and coding region (yellow line). Whole gene (upper) and close-up view surrounding the substitution variant (lower) are included with gene sequence at the bottom. Location of the substitution variant is indicated in blue for NCBI and Ensembl databases.
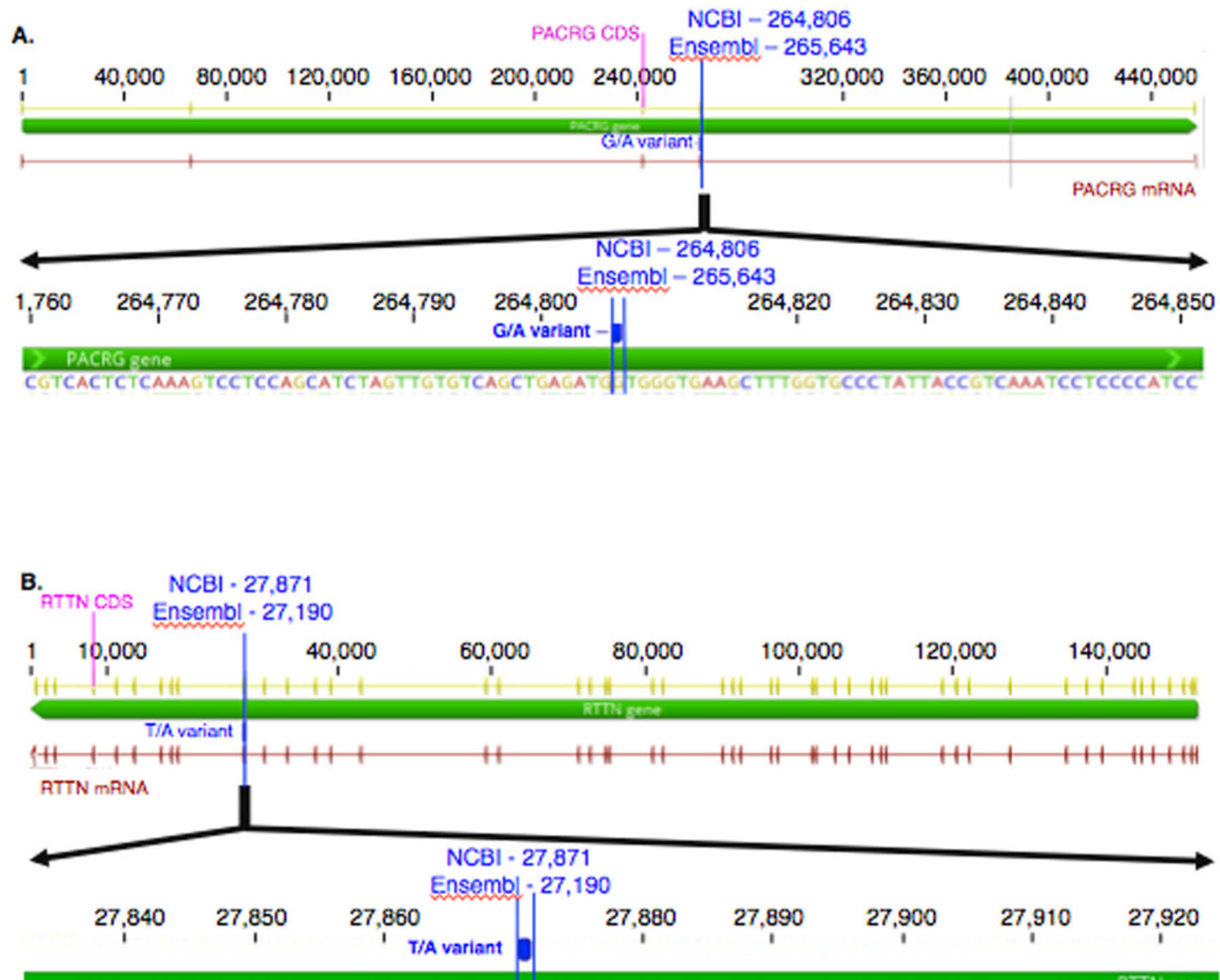


\section{Figure 2}

Alignment of wild type (WT) and mutant (mut) PACRG proteins with associated predicted hydrophobicity and isoelectric point.

Replacement of methionine for valine at position 182 changes a beta strand to an alpha helix at position 187 and 188. Alpha helices (pink), coils (gray line), turns (blue arrows) and beta strands (yellow arrows).

A.

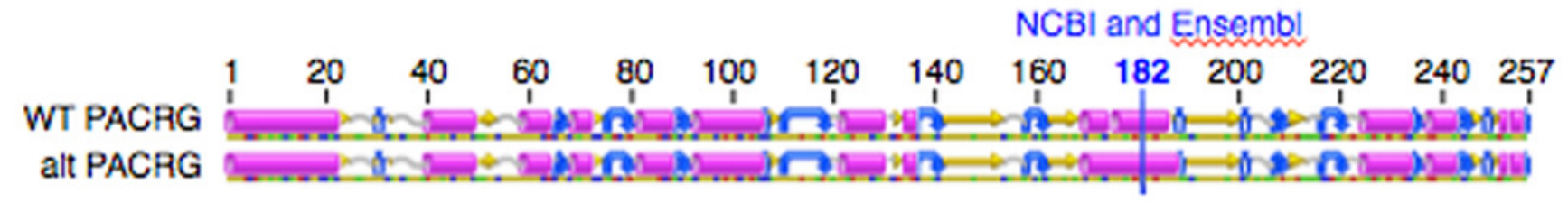

B.
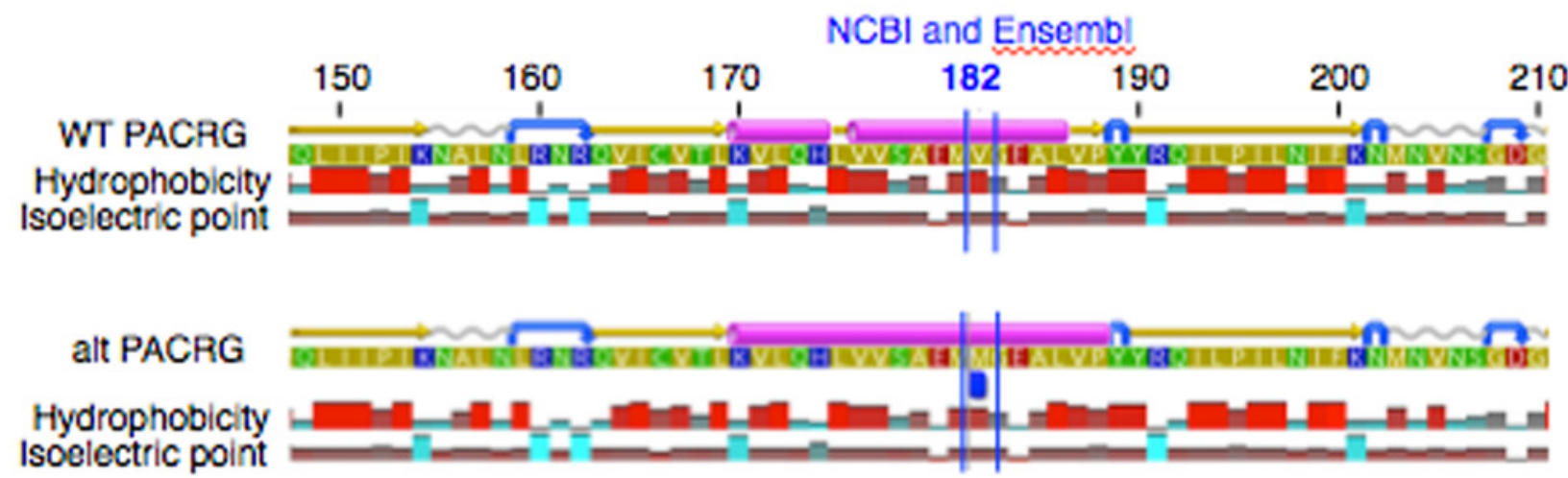


\section{Figure 3}

Alignment of WT and mutant RTTN protein with predicted hydrophobicity and isoelectric point.

Replacement of arginine with tryptophan at position 1812 changes alpha helix to beta strand at position 1816. Alpha helices (pink), coils (gray line), turns (blue arrows) and beta strands (yellow arrows).

NCBI 1812

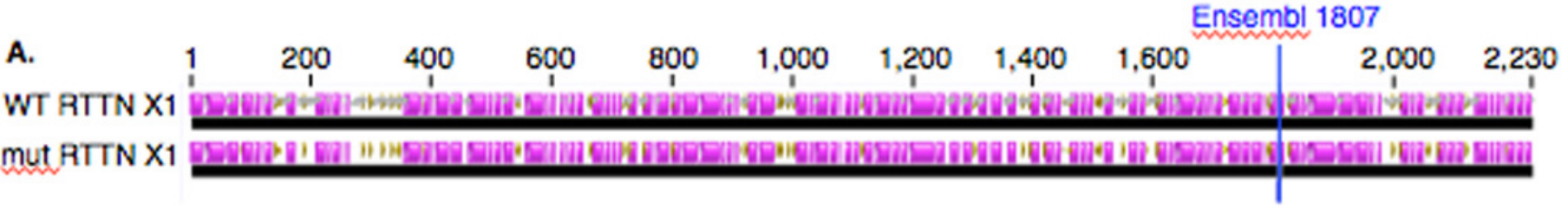

B.

WT RTTN X1 Hydrophobicity Isoelectric point

mut RTTN X1

Hydrophobicity Isoelectric point

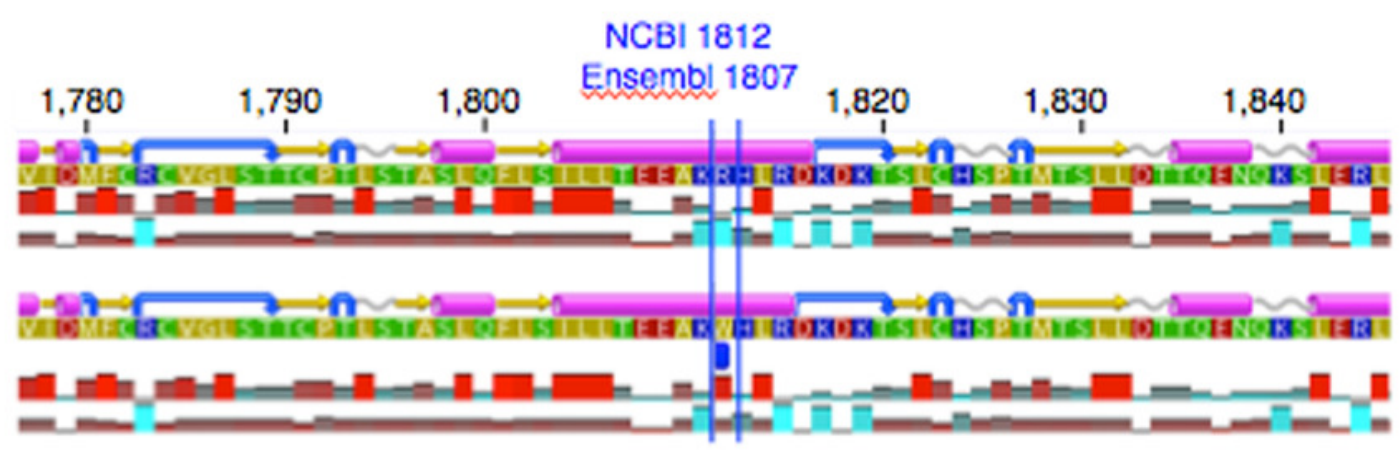


Figure 4

Expression of PACRG (A, B) and RTTN (C, D) in asthmatic and non-asthmatic horses in counts-per-million (CPM; $y$-axis) pre- and post-challenge.

PACRG expression varied from $\sim 30.7$ to 66.3 CPM in asthmatic horses $(A)$ and $\sim 25.1$ to 65.6 CPM on non-asthmatic horses (B), while RTTN expression varied from 11.5 to 24.9 CPM and 13.1 to 29.9 CPM in asthmatic (C) and non-asthmatic (D) horses, respectively.

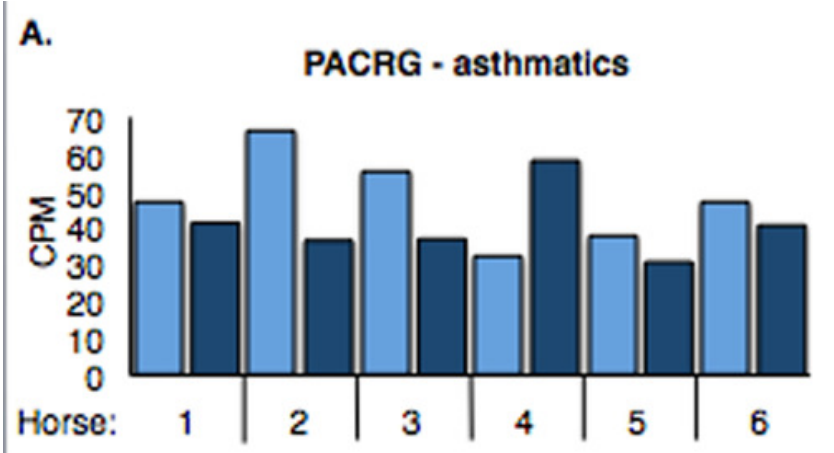

B.

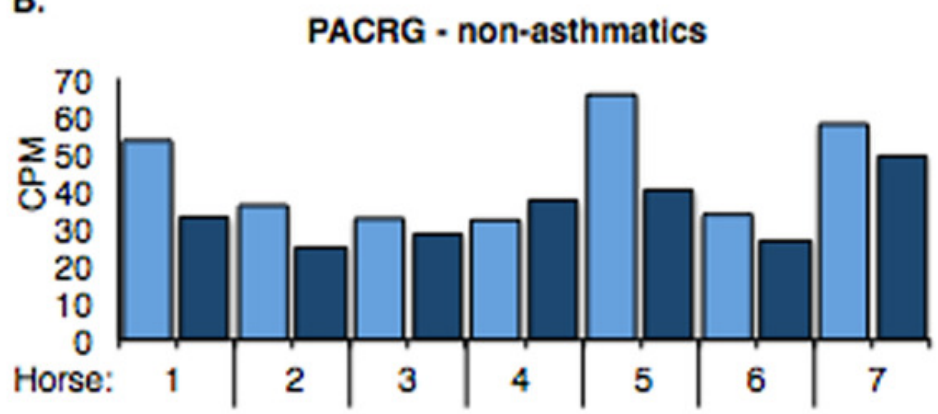

c.

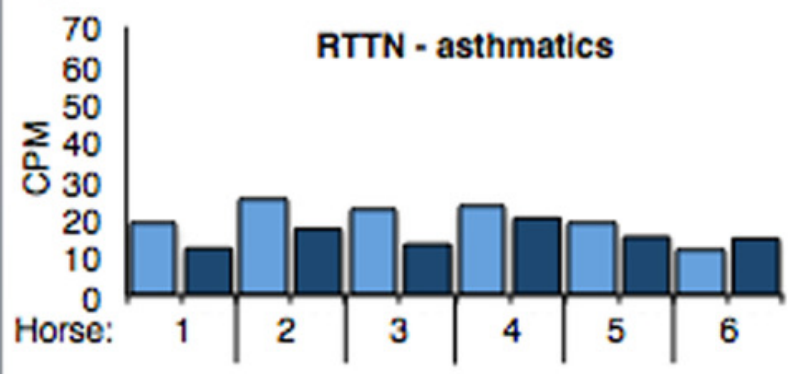

D.

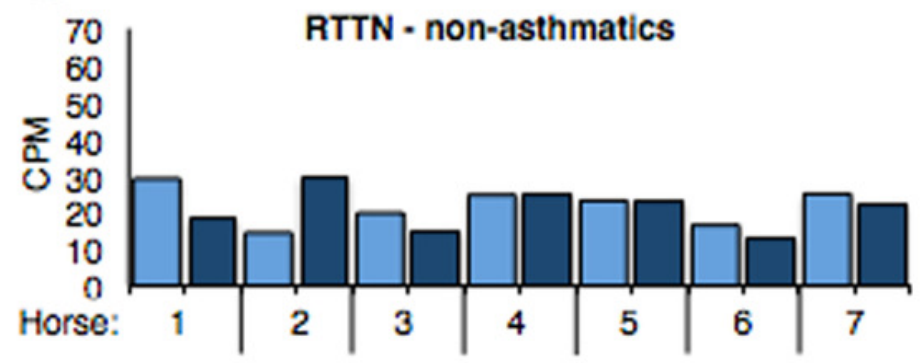

$\square$ Before asthmatic challenge

$\square$ After asthmatic challenge 


\section{Figure 5}

Comparison of GATK variant calls and Sanger sequencing results for PACRG in asthmatic (A) and non-asthmatic (B) horses.

For both groups, the bar graph indicates the IGV count for each allele (A-red, G-yellow), horse and condition. Below the bar graph is the GATK variant call, the electropherogram of the Sanger sequence, and agreement. (A) Four asthmatic horses $(1,2,5,6)$ had heterozygous alleles $[A / G]$ and two ( 3 and 4 ) were homozygous for the mutant allele $[A / A]$. (B) In nonasthmatic horses, one horse (6) had heterozygous alleles [A/G], three horses (1, 2 and 4) were homozygous for the wild-type allele $[G / G]$ and three horses $(3,5$ and 7$)$ were homozygous for the mutant allele [A/A]. All genotypes were consistent across horses and methods. DNA was not available for non-asthmatic horse 1. 


\section{PACRG RNA-Sea}

Allele count in asthmatic horses

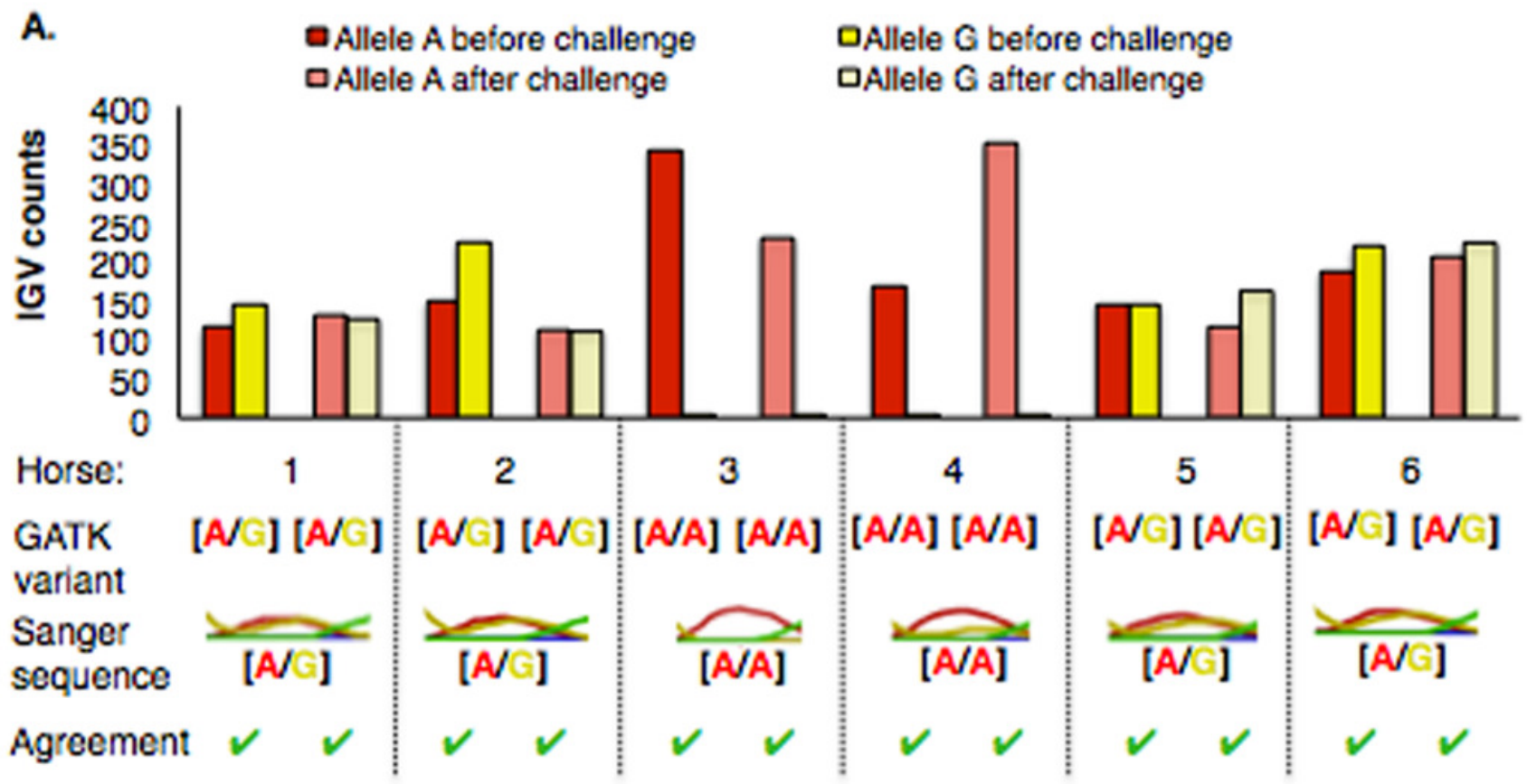

Allele count in non-asthmatic horses

B. -Allele A before challenge

口Allele $A$ after challenge

DAllele $G$ before challenge

DAllele $G$ after challenge

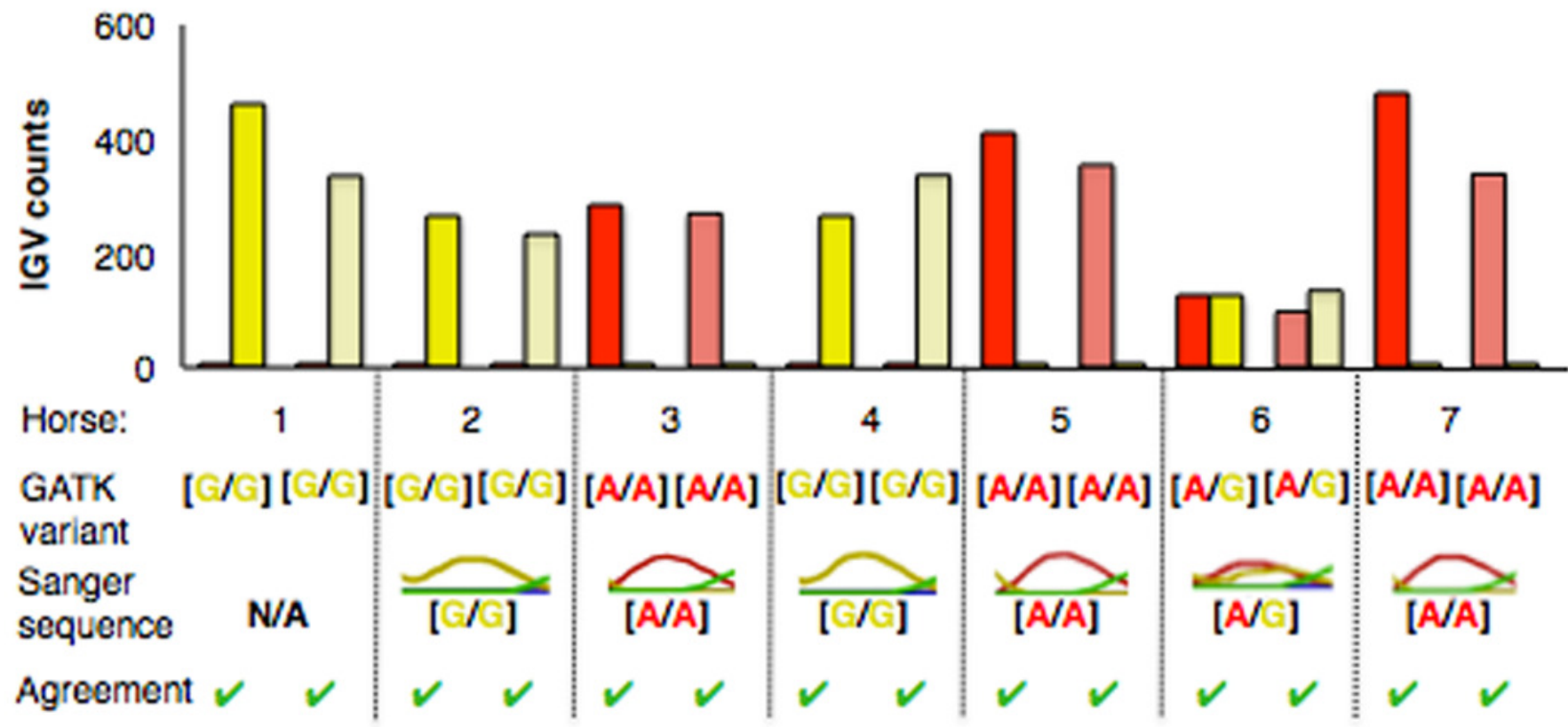




\section{Figure 6}

Comparison of GATK variant calls and Sanger sequencing results for RTTN in asthmatic (A) and non-asthmatic (B) horses.

Details as in Fig. 6. (A) Four asthmatic horses (3-6) had heterozygous alleles [A/T] and two (1 and 2) were homozygous for the mutant allele [A/A]. Genotypes were consistent across horses and methods. (B) In non-asthmatic horses, one (5) had heterozygous [A/T] alleles, four horses had homozygous wild type [T/T] alleles, and two horses (1 and 4) were inconsistently identified as homozygous wild type and heterozygous in different samples. Sanger sequencing confirmed the genotype of horse 4 as heterozygous. DNA was not available for non-asthmatic horse 1. 


\section{RTTN RNA-Sea}

A.

Allele count in asthmatic horses

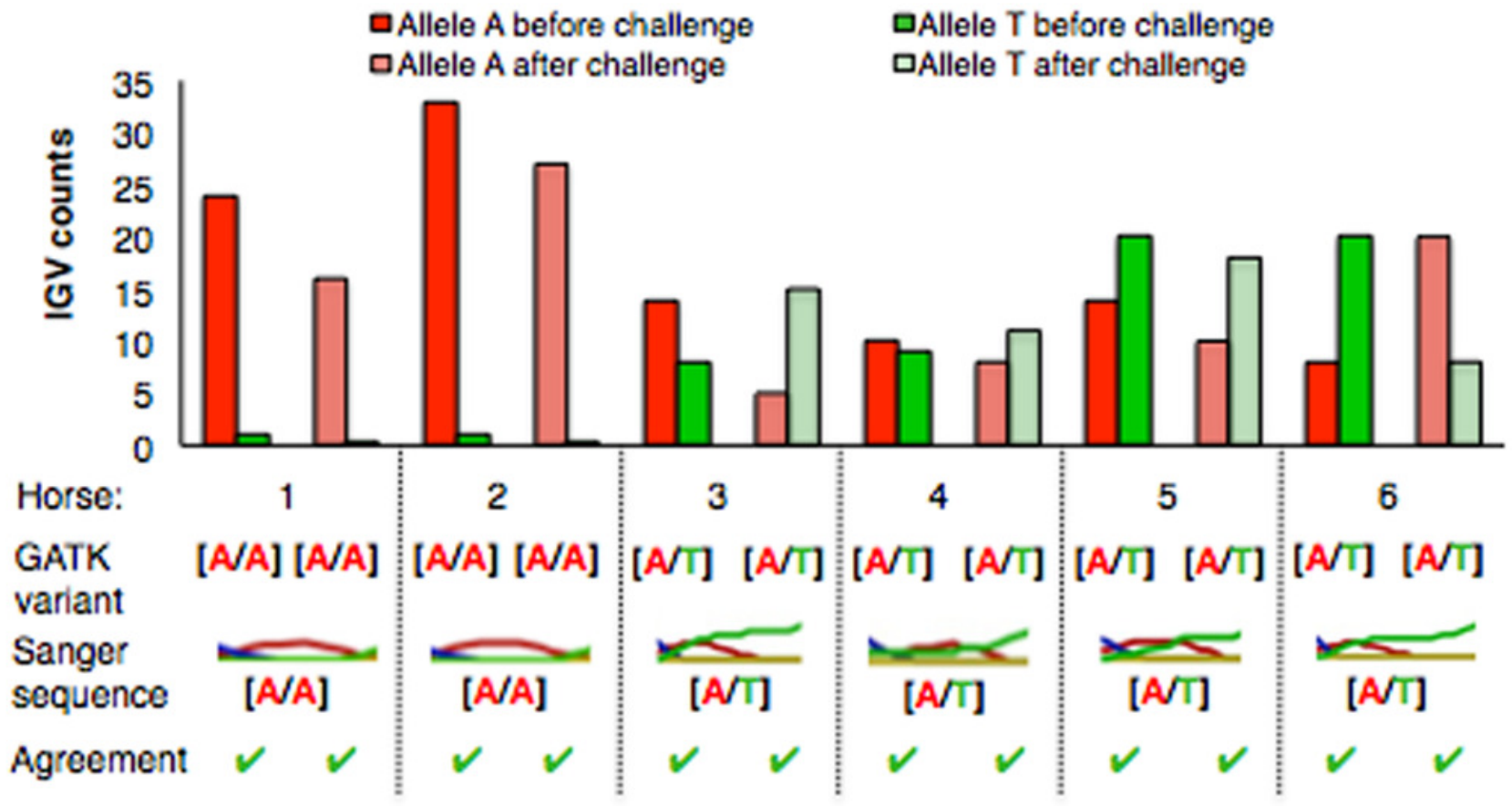

Allele count in non-asthmatic horses

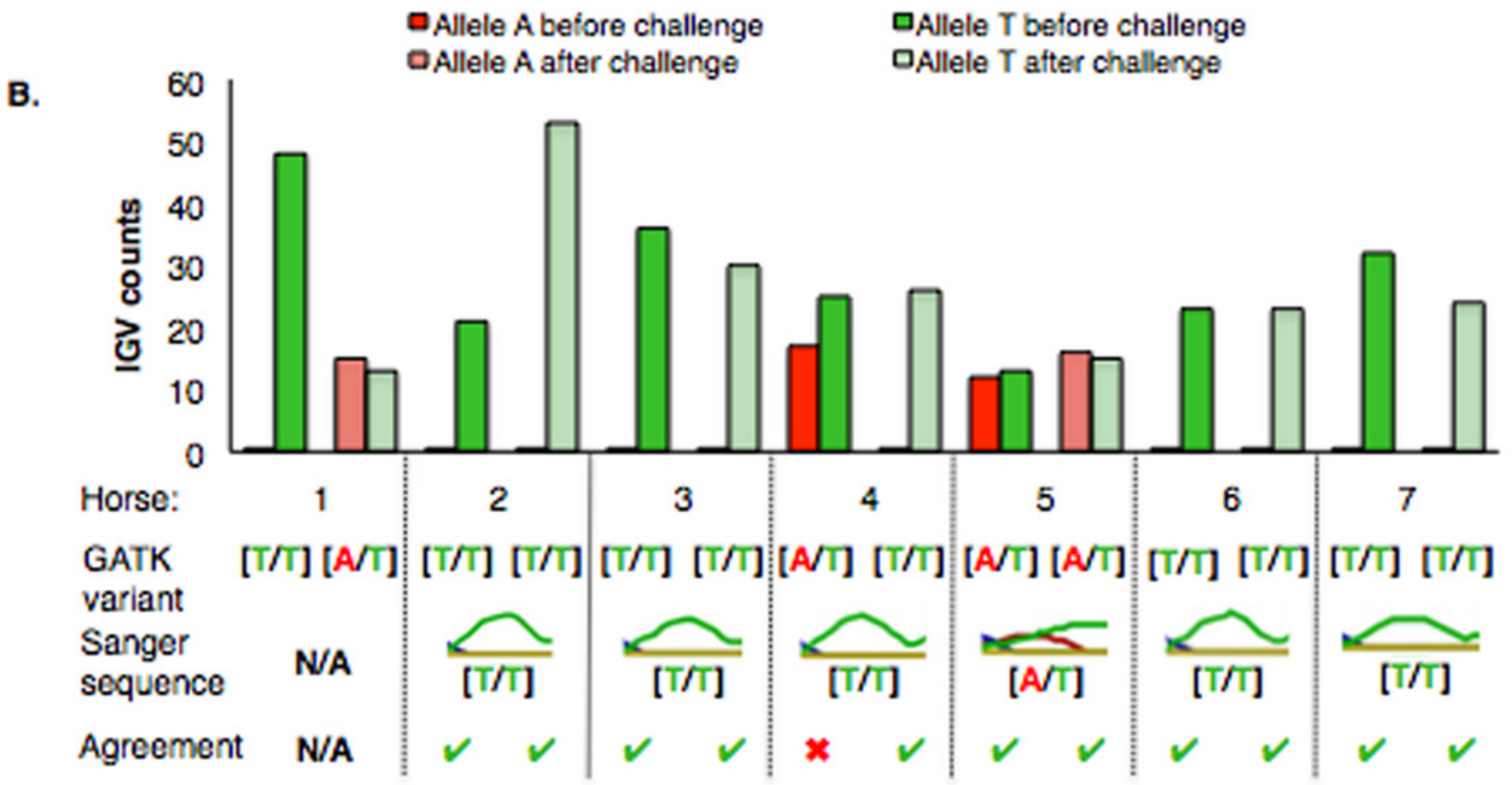




\section{Figure 7}

Alignment of PACRG (A) and RTTN (B) Sanger sequences for 10 asthmatic and 14 nonasthmatic horses with the reference genome.

(A) For PACRG, 8 asthmatic horses (80\%) were heterozygous [A/G], 2 (20\%) were homozygous mutant $[A / A]$ and none was homozygous wild-type $[G / G]$. Six non-asthmatic horses (43\%) were heterozygous [A/G], 5 (36\%) were homozygous mutant [A/A] and $3(21 \%)$ were homozygous wild type [G/G]. (B) For RTTN, in the asthmatic group, there were 5 (50\%) heterozygous $[\mathrm{A} / \mathrm{T}], 2(20 \%)$ homozygous mutant $[\mathrm{A} / \mathrm{A}]$ and $3(30 \%)$ homozygous wild type $[\mathrm{T} / \mathrm{T}]$ genotypes. In the non-asthmatic group, 4 (29\%) were heterozygous [A/G], 10 (71\%) were homozygous wild type $[T / T]$, and none had the homozygous mutant $[A / A]$ genotype. 
A.

Horse 1

Horse 2

Horse 3

Horse 4

Horse 5

Horse 6

Horse 7

Horse 8

Horse 9

Horse 10

Horse 1

Horse 2

Horse 3

है

Horse 4

Horse 5

Horse 6

Horse 7

Horse 8

Horse 9

Horse 10

Horse 11

Horse 12

Horse 13

Horse 14

Reference

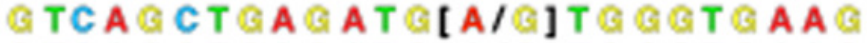

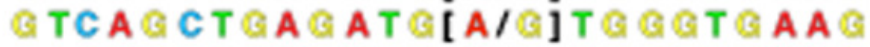
QTCA@CT@A@AT@[A/A]T@G@T@AAG QTCA@CT@A@AT@[A/A]T BQT@AA@

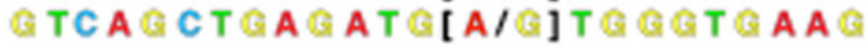
QTCA@CT@A@AT@[A/@]T@QBT@AA@

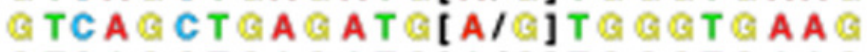
QTCA@CT@A@AT@[A/@]T@@QT@AA@

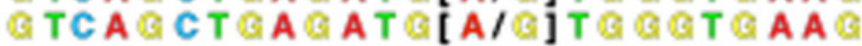

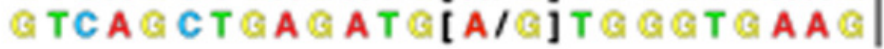

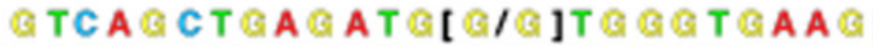

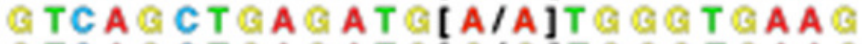

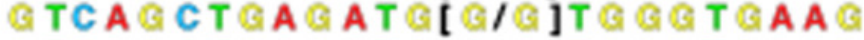

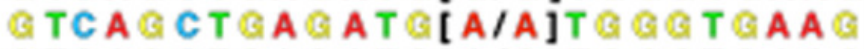
QTCA@CT@A@ATQ[A/Q]TQBQT@AA@

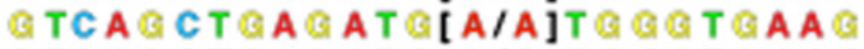
QTCA@CT@A@AT@[A/Q]TQBQT@AA@

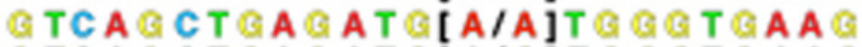

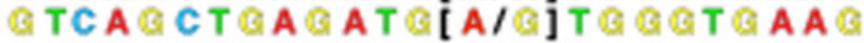

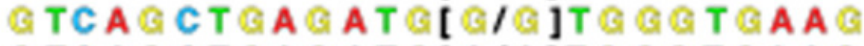

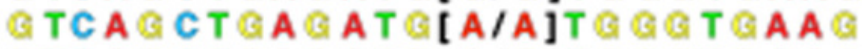

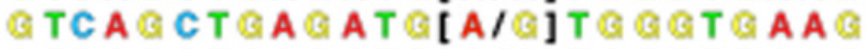

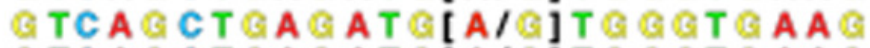
GTCA@CT@A@AT@[AI@]T@QBT@AA@|

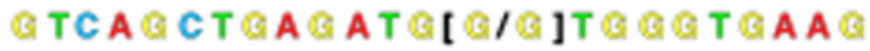

$$
\begin{aligned}
& {[A / A]=2(20 \%)} \\
& {[A / \Theta]=8(80 \%)} \\
& {[\odot / \Theta]=0(0 \%)}
\end{aligned}
$$$$
[A / A]=5(36 \%)
$$$$
[A / Q]=6(43 \%)
$$$$
[\otimes / \otimes]=3(21 \%)
$$

B.

Horse 1

Horse 2

Horse 3

Horse 4

Horse 5

Horse 6

Horse 7

Horse 8

Horse 9

Horse 10

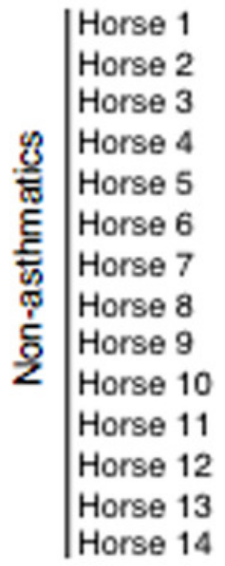

TCCCQ@A@AT@CC[A/A]TTTT@CTTCT TCCC@@A@AT@CC[A/A]TTTT@CTTCT TCCC@@A@AT@CC[A/T]TTTT@CTTCT

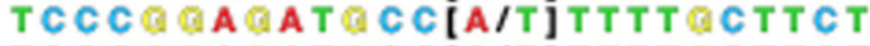

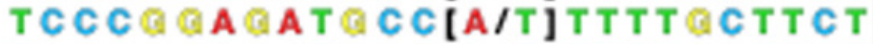

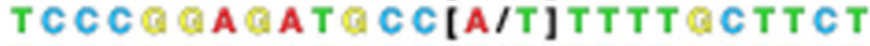
TCCC@@A@AT@CC[T/T]TTTT@CTTCT TCCC@@A@AT@CC[T/T]TTTT@CTTCT TCCC@@A@AT@CC[T/T]TTTT@CTTCT TCCC@QA@AT@CC[A/T]TTTT@CTTCT|

TCCC@@A@AT@CC[T/T]TTTT@CTTCT

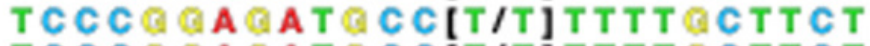
TCCC@@A@AT@CC[T/T]TTTT@CTTCT TCCC@@A@AT@CC[A/T]TTTT@CTTCT TCCC@@A@AT@CC[T/T]TTTT@CTTCT TCCC@@A@AT@CC[T/T]TTTT@CTTCT TCCC@@A@AT@CC[T/T]TTTT@CTTCT TCCC@@A@AT@CC[T/T]TTTT@CTTCT $T C C C @ A @ A T @ C C[A / T] T T T T @ C T T C T$ TCCC@aA@AT@CC[T/T]TTTT@CTTCT TCCC@@A@AT@CC[T/T]TTTT@CTTCT TCCC@@A@AT@CC[T/T]TTTT@CTTCT

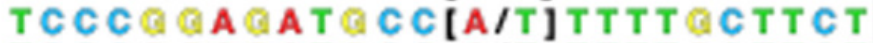

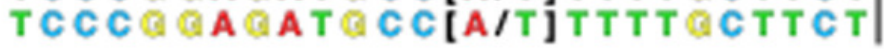

$[A / A]=2(20 \%)$

$[\mathrm{A} / \mathrm{T}]=5(50 \%)$

$[\mathrm{T} / \mathrm{T}]=3(30 \%)$
$[A / A]=0(0 \%)$

$[A / T]=4(29 \%)$

$[\mathrm{T} / \mathrm{T}]=10(71 \%)$ 